\title{
Coordinative Chain Transfer Polymerization
}

Andreia Valente, ${ }^{i, 1,2,3,4}$ André Mortreux, ${ }^{1,2,3,4}$ Marc Visseaux, ${ }^{1,2,3,4}$ Philippe Zinck* ${ }^{1,2,3,4}$

1 Univ Lille Nord de France, F-5900 Lille, France

2 ENSCL, UCCS, CCM, F-59652 Villeneuve d'Ascq, France

3 USTL, UCCS, CCM, F-59655 Villeneuve d'Ascq, France

4 CNRS, UMR8181, F-59652 Villeneuve d'Ascq, France

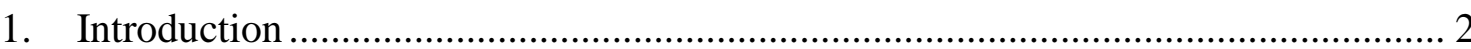

2. Coordinative chain transfer polymerization of single monomers ........................... 5

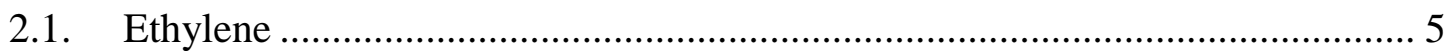

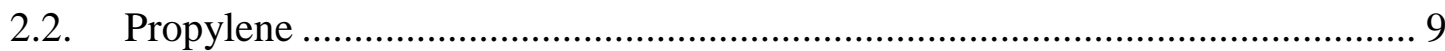

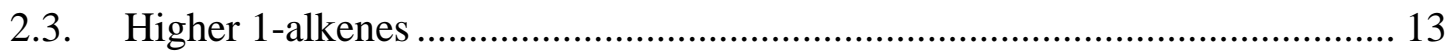

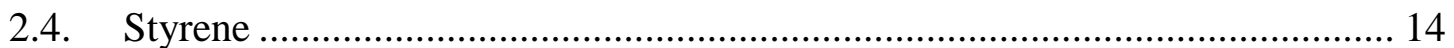

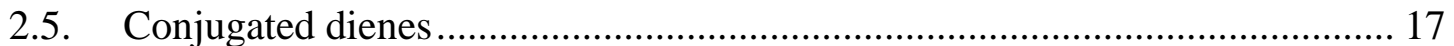

3. Statistical Coordinative Chain Transfer co-Polymerizations (CCTcoP)................. 23

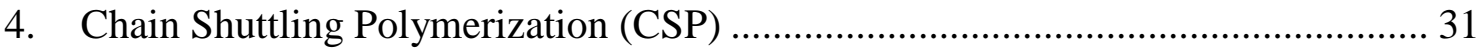

4.1. CSP combined to Chain Walking Polymerization ....................................... 31

4.2. CSP between enantiopure catalysts in a racemic mixture …........................ 31

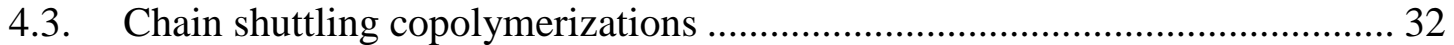

\footnotetext{
' Current adress: Centro de Ciências Moleculares e Materiais, Faculdade de Ciências da Universidade de Lisboa, Campo Grande, 1749-016 Lisboa, Portugal
} 


\section{Introduction}

The development of single-site catalysts has led to great potentialities for finetuning the microstructure of polyolefins and polydienes. Both regioselectivity and stereoselectivity of the polymerization can be controlled, together with the growth of well-defined branches onto the macromolecular backbone. Various types of microstructures and architectures are now reachable, particularly under conditions where a living polymerization is occurring, i.e. one molecule of catalyst leads to the growth of only one macromolecular chain (Scheme 1a). In order notably to reduce the consumption of highly expensive transition metal based catalysts and to control the molecular weight of the polymer, strategies enabling the growth of several macromolecular chains per catalyst, such as Coordinative Chain Transfer Polymerization (CCTP), have been developed. ${ }^{1-8}$ CCTP involves the use of a single transition metal based catalyst and a chain transfer agent (CTA), usually in the form of a main group metal alkyl. In this case, the growing macromolecular chain is able to transfer from the catalyst (active species) to the chain transfer agent, which is usually considered as a dormant species in the course of the polymerization, via transalkylation. CCTP is thus a degenerative group transfer polymerization, i.e. a process involving a dynamical equilibrium between propagating and dormant species (Scheme 1b). In contrast with a classical living polymerization where each molecule of catalyst affords the growth of a single polymer chain (Scheme 1a), chain transfer from the catalyst to the CTA allows the growth of several polymer chains per catalyst molecule (Scheme 1b). The transfer has to be rapid $v s$. propagation, reversible, and other chain termination pathways, such as $\beta \mathrm{H}$ abstraction, must not occur, or occur in a negligible way. Narrow molecular weight distributions are obtained, and the macromolecular chains are endcapped with the chain transfer metal, enabling further functionalization based on the 
chemistry of the main group metal. This can be viewed, as proposed by Gibson ${ }^{2}$ and Kempe $^{5}$, as a metal complex catalyzed Aufbaureaktion. ${ }^{9}$ If the chain transfer efficiency ${ }^{10}$ is high, i.e. most of the alkyl groups are involved in the transmetalation, the polymer appears to be growing on the main-group metal alkyl. These latter reactions involving fast and reversible transfer together with high transfer efficiencies and the non-occurrence of other chain termination pathways (i.e. CCTP with quantitative transfer efficiency $v s$. CTA) are conceptually close to controlled radical polymerization. ${ }^{11}$ They were given the name of Catalyzed Chain Growth (CCG). ${ }^{2}$ Note that this should not be confused with catalytic chain growth referring to metal-catalyzed olefin insertion into a growing alkyl chain. CCG reactions are interesting in terms of atom economy but also for the synthesis of block copolymers starting from the resulting polymer. For block copolymer synthesis, the chain transfer efficiency must be quantitative because, upon addition of the second monomer, the residual main group metal alkyls can lead to the growth of a homopolymer chain of the second monomer, resulting in a blend of block copolymer and homopolymer requiring purification workup in order to recover the block copolymer pure.

In addition to the transfer efficiency, the ratio between the chain transfer agent and the catalyst is also a parameter of importance. Indeed, the higher this ratio and the higher the transfer efficiency, the higher the number of chains that can be grown per expensive catalyst molecules. This can be considered as a catalyst economy.

CCTP and CCG reactions thus afford a controlled polymerization in the absence of termination pathways other than chain transfer to the CTA which is of particular interest for monomers such as ethylene that are scarcely polymerizable via anionic or radical polymerizations. The coordination of the monomer on the transition metal in the course of the polymerization gives access to a stereoselective polymerization. This is of 
particular interest for monomers, such as olefins and dienes (e.g. 1,4-trans stereoselective polymerization of 1,3 conjugated dienes, syndiospecific polymerization of propylene, styrene, etc...), as the stereoselective character cannot be achieved by classical living polymerizations (i.e. anionic and controlled radical polymerizations). Early CCTP studies were motivated by the beneficial effect that can be expected in terms of catalyst economy, control over the molecular weight and end-functionalization of the resulting polymer. Studies conducted in the recent years were in turn oriented toward catalytic systems for CCTP able to finely control the microstructure and the architecture of the polymer, in order to access to original macromolecular enchainments exhibiting new properties. In a cutting-edge study, Arriola and coworkers reported the straightforward synthesis of a new class of thermoplastic elastomers. ${ }^{3}$ Multi-block ethylene/1-octene copolymers with sequential crystallizable (low 1-octene content) and non-crystallizable (high 1-octene content) statistical copolymer segments were synthesized via chain shuttling copolymerization (Scheme 2). Such an original microstructure results from the simultaneous presence in the reactive medium of chains growing on two different catalysts and of a chain transfer or chain shuttling agent. The co-monomer reactivity ratios are different for the two catalysts, leading to ethylene-rich and 1-octene-rich segments. The chains are able to growth in a sequential way on the two different catalysts via transfer to the chain shuttling agent. This concept referred to as Chain Shuttling Polymerization (CSP) has been highlighted in numerous perspective articles. $^{12}$

The present review will be devoted to CCTP with a focus on the factors enabling decreased occurrence of termination pathways other than transfer to the CTA such as $\beta \mathrm{H}$ abstraction and on the new concepts that can be derived for the control of the microstructure and the architecture of the resulting polymers. End-functionalizations 
will not be dealt with, and interested readers are invited to consult other reviews on this subject. ${ }^{13}$ We will discuss the CCTP of single monomers, including ethylene, propylene and higher 1-alkenes, styrene and conjugated dienes. A particular emphasis will be given to the microstructure. As the CCTP of ethylene has been reviewed in $2007,{ }^{5}$ we will focus on the work published after this period and briefly present the main earlier studies. We will further present the application of CCTP to statistical copolymerizations and the resulting new concepts that have been derived. ${ }^{14}$ The last part of this article will be devoted to chain shuttling polymerizations, including a brief discussion of the properties of the resulting polymers showing unprecedented microstructure and architecture.

\section{Coordinative chain transfer polymerization of single monomers}

\subsection{Ethylene}

The CCTP of ethylene has been reviewed in $2007 . .^{5}$ We thus present in this section a brief overview of the field, together with the studies published in the period 2007-2012. The different pre-catalysts used for ethylene CCTP are presented in Figure 1. Chain growth on a main group metal was first shown to proceed via a stepwise insertion of ethylene into the Al-C bonds at high temperature and pressure. ${ }^{9}$ Catalyzed versions of this reaction were proposed under smoother conditions with transition metals and rare earths using aluminum, ${ }^{15-27}$ zinc $^{2 ; 28-31}$ and magnesium alkyls ${ }^{1}$ as chain transfer agents.

The polyethylene chain transfer reaction using a main group metal and a transition metal based catalyst have been described in the patent literature to occur with $\mathrm{AlEt}_{3}$ as the chain transfer agent and activated hafnocenes ${ }^{15}$ leading to Schulz-Flory distributions of aluminium alkyl chains. Actinidocenes ${ }^{16}$ gave in turn rise to Poisson 
distributions under similar conditions, but the transfer efficiency cannot be calculated using the reported data. Using the samarocene precatalyst $\underline{\mathbf{1 a}}$ combined with dialkylmagnesium at $80{ }^{\circ} \mathrm{C}$ and 1.01 bar ethylene, Mortreux et al. ${ }^{1}$ obtained with a $100 \%$ efficiency long chain dialkylmagnesium Grignard type reagents with a narrow polydispersity (Scheme 3). The resulting narrow polymer molecular weight distribution was found to be described by a Poisson distribution. The analogous neodymocene and yttrocene complexes $\underline{\mathbf{1 b}}$ and $\underline{\mathbf{1 c}}$, were found to behave similarly. It should be noted that chain transfer reactions were later observed between the neodymocene $\mathbf{1 b}$ and aluminum using an equimolar mixture of $\mathrm{BuLi}$ and $\mathrm{AlH}^{i} \mathrm{Bu}_{2}$ as co-catalyst, with the simultaneous occurrence of $\beta \mathrm{H}$ abstraction. ${ }^{26}$

Aminopyridine yttrium compounds were used by Kempe et al. for the ethylene CCTP between organoyttrium cations derived from $\underline{\mathbf{2}}$ and aluminum (tetraisobutylaluminoxane) using 5 bar of ethylene pressure (Scheme 4$){ }^{21}$ The stability of organoyttrium cations at $80{ }^{\circ} \mathrm{C}$ allowed the synthesis of relatively long-chain Alterminated polyethylenes ( $\mathrm{Mn}$ up to $4000 \mathrm{gmol}^{-1}$ ) with a narrow molecular weight distribution $\left(\mathrm{B}_{\mathrm{M}}<1.1\right)$. At higher temperatures $\left(100{ }^{\circ} \mathrm{C}\right)$, polymers with molecular weights up to 15600 gmol $^{-1}$ could be obtained at the expense of the dispersity $\left(\mathrm{B}_{\mathrm{M}} \approx\right.$ 1.4). This effect was caused by the increase in the solution viscosity and consequent polymer precipitation. More recently, a series of amidinate supported organoyttrium cations derived from $\underline{\mathbf{3}}$ allowed, at $80{ }^{\circ} \mathrm{C}$ and in combination with an excess of homoleptic trialkylaluminum compounds $\left(\mathrm{AlR}_{3}, \mathrm{R}=\mathrm{Et},{ }^{i} \mathrm{Bu}, n\right.$-Oct $)$, a highly controlled ethylene CCTP, producing Al terminated polyethylenes (Mn up to $4200 \mathrm{gmol}^{-1}$ ). ${ }^{24}$

The chromium (III) precatalyst $\underline{\mathbf{4}}$, when activated with $\mathrm{B}\left(\mathrm{C}_{6} \mathrm{~F}_{5}\right)_{3}$, and in combination with methylaluminoxane $(\mathrm{MAO})$ in toluene $\left(\mathrm{Al} / \mathrm{Cr}=1000,23{ }^{\circ} \mathrm{C}, 1.01 \mathrm{bar}\right.$ ethylene) produced low molecular weight ethylene oligomers. ${ }^{17,18}$ Despite the low 
polymerization temperatures, no precipitation was observed. In the presence of 415 equiv. of $\mathrm{Al}_{2} \mathrm{Me}_{6}$ in addition to the 1000 equiv. MAO, the GCMS (gas chromatography - mass spectroscopy) chromatogram revealed a shift in the distribution in favour of shorter alkanes which was accompanied by an overall activity decrease as well. This slower rate of ethylene consumption was explained by the formation of bridging species (Scheme 5), similar to binuclear neodymium-magnesium complexes initially suggested to account for the same behaviour upon increasing the $\mathrm{Mg} / \mathrm{Nd}$ ratio in Mortreux's studies. ${ }^{1 \mathrm{a}}$ Using the neutral chromium allyl $\underline{\mathbf{5}}$ without any activator, the polymerization of ethylene proceeded with a rapid precipitation of the polymer in toluene, at room temperature and 1.11 bar of ethylene pressure. ${ }^{19}$ In the presence of $\mathrm{AlEt}_{3}$, the activity of the system decreased, and the resulting polymers were shorter (up to $500 \mathrm{gmol}^{-1}$ ), indicating transmetalation reactions to the aluminum centre (Scheme 6). Similar results were observed using $\left[\mathrm{Cp}^{*} \mathrm{Cr}\left(\mathrm{C}_{6} \mathrm{~F}_{5}\right)(\mathrm{Bn})(\mathrm{THF})\right](\mathrm{Bn}=$ benzyl $) \underline{\mathbf{6}}$, in combination with an excess of $\mathrm{AlEt}_{3}{ }^{20}$

Gibson and coworkers used the bis(imino)pyridine iron(II) dichloride complex $\underline{\mathbf{7}}$ in combination with MAO as cocatalyst and diethylzinc as chain transfer agent. ${ }^{2,28}$ This catalytic system allowed the first Catalyzed polyethylene Chain Growth on zinc (Scheme 7). The polymerizations were performed under much smoother conditions than those using rare-earth pre-catalysts, i.e., 1.0 bar of ethylene pressure at room temperature, affording molecular weights up to $3000 \mathrm{gmol}^{-1}$ in transmetalation conditions. A detailed examination of the factors enabling this iron CCG led the authors to propose the key features for this process: i) relatively low steric hindrance around the zinc centre; ii) the monomeric nature of $\mathrm{ZnEt}_{2}$ in solution; iii) the relatively weak $\mathrm{Zn}-\mathrm{C}$ bond; and iv) a reasonably close match in $\mathrm{Zn}-\mathrm{C}$ and $\mathrm{Fe}-\mathrm{C}$ bond strengths. Concerning i), a direct correlation between the size of the ligand on the main group metal and the 
extent of the observed chain transfer to the CTA was noticed. Additionally, the data showed that the CTA having a monomeric nature in solution are more active. Relatively to iii) and iv), a fine balance between these factors was needed to generate a catalyst latent state which is stable, yet highly reactive. A later study proved these findings to be relevant. $^{29}$

The methyl monocyclopentadienyl amidinate hafnium complex $\underline{\mathbf{8}}$ in combination with a borate activator was found to be an efficient catalytic system for the CCTP of ethylene in the presence of various molar amounts of $\mathrm{ZnR}_{2}\left(\mathrm{R}=\mathrm{Et}\right.$ or ${ }^{i} \mathrm{Pr} ; 20-200$ equiv.) in toluene at $25{ }^{\circ} \mathrm{C}$ under $\approx 1.34$ bar of ethylene pressure, producing polyethylene with molecular weights up to $670 \mathrm{gmol}^{-1}$ (Scheme 8$) .^{30}$ Besides the nonoccurrence of chain termination by $\beta$-hydrogen transfer, the reversible transfer and living character of these reactions was supported by a kinetic study by GC, which revealed a narrow Poisson distribution.

A hafnium pyridyl-amide catalyst $\underline{\mathbf{9}}$ was assessed for ethylene CCTP in combination with $\mathrm{AlOct}_{3}$ as CTA. ${ }^{23}$ Fairly constant polymer yields were obtained with increasing quantities of CTA. The dispersity values were lower than 2 , and decreased monotonically with the addition of CTA. Concerning the chain transfer efficiency, less than half of the available $\mathrm{Al}$ sites were occupied by polymer chains. This indicated that polymeryl-polymeryl exchange is kinetically competitive with polymer-alkyl exchange in this system.

A series of new aminopyridinato ligand stabilized hafnium complexes were also assessed for ethylene polymerization. ${ }^{25}$ The catalyst giving the highest level of control, $\underline{\mathbf{1 0}}$, in the presence of high amounts of $\mathrm{AlEt}_{3}$, produces linear aluminum-terminated polyethylene without significant $\beta-\mathrm{H}$ abstraction. However, this first study showed that 
the transfer was relatively slow in relation to chain growth which leads to a lack of control over the molecular weight distribution.

The reversible chain transfer to $\mathrm{Al}$ in ethylene polymerization catalyzed by $\mathrm{Cp}_{2}^{*} \mathrm{ZrCl}_{2} \underline{11} / \mathrm{MAO}$ was also studied via comparison of the polymerization in the presence and absence of $\mathrm{AlMe}_{3}$ contained in commercial MAO. ${ }^{27}$ The molecular weight distributions of the products were found to be narrower in the presence of $\mathrm{AlMe}_{3}$ at low $\mathrm{Al} / \mathrm{Zr}$ ratios. Dispersities of about 1.3 or lower were attainable at temperatures up to 70 ${ }^{\circ} \mathrm{C}$. A fast to moderate reversible chain transfer between $\mathrm{Cp}^{*}{ }_{2} \mathrm{ZrR}^{+}$and $\mathrm{AlMe}_{3}$ was suggested in order to explain the decrease of the dispersity.

\subsection{Propylene}

Many of the pre-catalysts reported to afford chain transfer in the course of propylene polymerization are based on $\mathrm{Zr}^{32-39}$ The first true CCTP of propylene was achieved recently by Sita and coworkers. ${ }^{40}$

The influence of aluminum alkyl on the chain transfer polymerization of propylene was carried out in the presence of zirconium catalyst precursors (Figure 2, racethylenebis(indenyl)-zirconium dichloride $\underline{\mathbf{1 2}}$, rac-dimethylenebis(indenyl)zirconium dichloride $\underline{\mathbf{1 3 b}}$ and isopropylidene(cyclopendadienyl)(9-fluorenyl)zirconium dichloride 14) in combination with triphenylcarbenium tetrakis(pentafluorophenyl)borate $\left(\mathrm{Ph}_{3} \mathrm{CB}\left(\mathrm{C}_{6} \mathrm{~F}_{5}\right)_{4}\right.$ or trityl borate $)$ and $\mathrm{AlEt}_{3}$ or $\mathrm{Al}^{i} \mathrm{Bu}_{3} .{ }^{36}$ In the isospecific polymerization with $\underline{\mathbf{1 2}}$ and $\underline{\mathbf{1 3 b}}$, the molecular weight of the resulting polymer was found to decrease with an increase in the molar ratio of $\mathrm{AlEt}_{3}$ vs. $\mathrm{Zr}$ catalyst. An effect of the $\mathrm{Al}^{i} \mathrm{Bu}_{3}$ concentration on molecular weight was in turn not observed. The considerably higher chain transfer efficiency of linear alkyl groups $v s$. isobutyl groups was also observed by Gibson et al. in the course of the polymerization of ethylene using $\underline{\mathbf{7}}$ in combination 
with aluminum alkyls. ${ }^{2}$ The microstructure of the resulting polypropylene was studied by ${ }^{13} \mathrm{C}$ NMR. An increase in the molar ratio of ethyl end groups (derived from chain transfer to $\mathrm{AlEt}_{3}$ ) to $n$-propyl end groups (derived from $\beta$-hydrogen transfer and consecutive insertion of propylene into the metal hydride) was observed with increase in the $\mathrm{AlEt}_{3} / \mathrm{Zr}$ molar ratio. $\mathrm{Al}^{i} \mathrm{Bu}_{3}$ was in turn found to lead to chain transfer when the polymerization was conducted with $\underline{\mathbf{1 4}}$, but its chain transfer efficiency remained lower than that observed using $\mathrm{AlEt}_{3}$, confirming the aforementioned trend on linear vs. $n$ propyl alkyl groups. The relative constants of chain transfer to aluminum alkyl vs. chain propagation $\mathrm{k}_{\mathrm{tr}} / \mathrm{k}_{\mathrm{p}}$ were found to be 5 times higher for $\mathrm{AlEt}_{3} v s . \mathrm{Al}^{i} \mathrm{Bu}_{3}$ in the course of the syndiospecific polymerization of propylene using $\underline{\mathbf{1 4}}$ and $\left(\mathrm{Ph}_{3} \mathrm{CB}\left(\mathrm{C}_{6} \mathrm{~F}_{5}\right)_{4}\right)$.

The aforementioned $\beta \mathrm{H}$ abstraction occurring using $\underline{\mathbf{1 3 b}}$ could be suppressed using MAO containing $\mathrm{AlMe}_{3}$ instead of trityl borate / $\mathrm{AlR}_{3}$ as co-catalyst, and performing the reaction at low temperature $\left(10{ }^{\circ} \mathrm{C}\right) .{ }^{35}$ It was shown that the relative frequencies of chain terminations via both $\beta$-hydride and $\beta$-methyl transfer reactions gradually decrease with the decrease of polymerization temperature.

Propylene polymerization was also conducted using $\left[\eta^{3} \cdot \eta^{1}\right.$-tertbutyl(dimethylfluorenylsilyl)amido]dimethyltitanium $\underline{\mathbf{1 5}}$ combined with $\mathrm{B}\left(\mathrm{C}_{6} \mathrm{~F}_{5}\right)_{3}$ or MAO as cocatalyst in the presence of various trialkylaluminum CTA $\left(\mathrm{AlMe}_{3}, \mathrm{AlEt}_{3}\right.$, $\mathrm{Al}^{i} \mathrm{Bu}_{3}$ and $\left.\mathrm{AlOct}\right)_{3} .^{41}$ Living polymerization was afforded at $-50{ }^{\circ} \mathrm{C}$ with $\mathrm{B}\left(\mathrm{C}_{6} \mathrm{~F}_{5}\right)_{3}$ as cocatalyst and using $\mathrm{AlEt}_{3}$ as CTA, giving Al-terminated polymers. AlOct 3 could act as an efficient CTA for high loadings only, while $\mathrm{AlMe}_{3}$ and $\mathrm{Al}^{i} \mathrm{Bu}_{3}$ produced only oligomers. When MAO was used as cocatalyst, the temperature needed to be increased to $40^{\circ} \mathrm{C}$ to observe a chain growth transfer which in this case strongly depends on the structure and electronic properties of the substituents on the CTA, which obviously must affect at least the rate of the first transfer step. 
The isospecific zirconocene catalyst $\mathrm{Me}_{2} \mathrm{Si}\left(2-\mathrm{Me}-4-{ }^{t} \mathrm{Bu}-\mathrm{C}_{5} \mathrm{H}_{2}\right)_{2} \mathrm{ZrCl}_{2} \underline{\mathbf{1 6}}$ was also used in combination with trimethylaluminum and MAO, and chain transfer of the growing polypropylene chains to aluminum was thus observed. ${ }^{32}$ The polymerizations were carried out in the presence of an excess of MAO ([Al]:[Zr] $=2000: 1$ ) to give highly stereoregular (95-99\% $[\mathrm{mmmm}])$ and regioregular (100\% 1,2 -insertions) polypropylene with $\mathrm{DP}_{\mathrm{n}}$ (number-average degree of polymerization) in the range 80150. ${ }^{13} \mathrm{C}$ NMR studies of these polymers showed high contents of isopropyl end chains, proving that the growing polymer chains are transferred from $\mathrm{Zr}$ to Al. Using an excess of $\mathrm{AlMe}_{3}$ in addition to $\mathrm{MAO}\left(\mathrm{AlMe}_{3}:[\mathrm{Zr}] \approx 500-5000: 1\right)$ generated even shorter polymer chains, as expected in a chain transfer mechanism (Scheme 9), and the activity was increased.

The zirconocene catalyst $\underline{\mathbf{1 7}}$ was used by Rieger et al. in combination with MAO or trityl borate in order to study the influence of reversible chain transfer in the polypropylene microstructure. ${ }^{33}$ When MAO was used, transmetalation reactions between the catalyst and the aluminum centre were observed, together with a change in the stereoselectivity of the reaction. The authors proposed that the reversible chain transfer to aluminum is involved in the stereoerror formation. As a consequence, a pallet of materials with crystalline and amorphous segments could be synthesized, allowing to envisage applications in terms of microstructure control. Using several techniques, such as NMR, differential scanning calorimetry (DSC), wide angle X-ray scattering (WAXS) and scanning force microscopy (SFM), the distribution of stereoerrors along the polymer chain could be identified. Using MAO, a statistical polymer was obtained with increasing amounts of longer isotactic sequences with crystallizable blocks consisting of 23-32 monomers in isotactic sequences, which co-crystallized in different lamellae 
phases. Better activities were obtained using oxygen-substituted asymmetric zirconocene dichlorides. $^{42}$

If chain transfer can play a role over the stereoselectivity of the reaction, the regioselectivity of the insertion of propylene can in turn influence the occurrence of chain transfer. Busico and coworkers ${ }^{43}$ observed that occasional regio-irregular 2,1 insertions occurring in the course of the isotactic polymerization of propylene using $\underline{\mathbf{1 2 a}}$ and 13a combined to MAO practically inhibit chain transfer to the monomer and to the aluminum alkyl cocatalyst.

The first true CCTP of propylene was reported by Sita et al. using $\mathrm{ZnEt}_{2}$ as CTA and the hafnium catalyst $\underline{\mathbf{8}}$ (Figure 1). ${ }^{30 ; 40}$ NMR spectroscopy shows that chain termination pathways other than chain transfer to the CTA do not occur in the course of the polymerization. An efficient reversible chain transfer (Scheme 10) was evidenced by (i) a strictly linear relationship between molecular weights and the initial molar equivalents of main-group metal alkyl, and (ii) the narrow molecular weight distributions of all isolated polypropylene products. Higher molecular weights could be obtained in the presence of 5 and 10 equiv. $\mathrm{ZnEt}_{2}$ using larger volumes of toluene and longer reaction times (atactic polypropylene is soluble under these conditions). This contrasts with polyethylene, where the polymer precipitation begins to occur for molecular weights around $2000 \mathrm{~g} / \mathrm{mol}^{1,21}$

Recently, Sita et al. extended the catalytic system to the $\underline{\mathbf{8}} / \mathrm{ZnEt}_{2} / \mathrm{AlR}_{3}(\mathrm{R}=$ ethyl, n-propyl, isobutyl) combination. ${ }^{44}$ The CCTP of propylene using trialkylaluminum as the single chain transfer agent showed similar results when compared to those obtained with diethylzinc. When both are used together, trialkylaluminium plays the role of the CTA and diethylzinc acts as a chain transfer mediator, enhancing the rate of the transfer reaction between catalyst $\underline{\mathbf{8}}$ and the 
aluminum alkyl (Scheme 11). Attempts to scale up the CCTP in volume were successfully accomplished using $10 \mathrm{~mol} \%$ of diethylzinc (relatively to triisobutylaluminum) in toluene under smooth conditions $\left(20^{\circ} \mathrm{C}, 1.34\right.$ bar) to produce atactic polypropylene with narrow molecular weight distributions. One key of this system is the possibility to use less of the more expensive $\mathrm{Zn}$ alkyl to get the same results.

\subsection{Higher 1-alkenes}

The application of CCTP to higher 1-alkenes is a rather emerging field. Using $\mathrm{Cp}^{*} \mathrm{HfMe}_{2}[\mathrm{~N}(\mathrm{Et}) \mathrm{C}(\mathrm{Me}) \mathrm{N}(\mathrm{Et})] \quad \underline{\mathbf{8}}$ as pre-catalyst and a borate activator $\left[\mathrm{PhNHMe}_{2}\right]\left[\mathrm{B}\left(\mathrm{C}_{6} \mathrm{~F}_{5}\right)_{4}\right]$, in combination with $\mathrm{ZnEt}_{2}$, Sita et al. reported the CCTP of 1hexene in toluene at $-10^{\circ} \mathrm{C}$ giving high yields of atactic poly(1-hexene) (Scheme 12). ${ }^{30}$ The molecular weights were found to be dependent on the initial molar equivalents of the main-group metal alkyl employed as CTA. A kinetic analysis confirmed the living character of the reaction.

Carpentier and Mortreux reported the use of the neodymium complexes [ rac$\left.\left\{\mathrm{Me}_{2} \mathrm{Si}\left(\eta^{5}-2-\mathrm{SiMe}_{3}-4-t-\mathrm{Bu}-\mathrm{C}_{5} \mathrm{H}_{2}\right)_{2}\right\} \mathrm{Nd}(\mu-\mathrm{Cl})_{2} \mathrm{Li}(\mathrm{THF})_{2}\right] \quad \underline{\mathbf{1 8 a}}, \quad\left[\mathrm{rac}-\left\{\mathrm{Me}_{2} \mathrm{Si}\left(\eta^{5}-2,4-\right.\right.\right.$ $\left.\left.\left(\mathrm{SiMe}_{3}\right)_{2}\left(\mathrm{C}_{5} \mathrm{H}_{2}\right)_{2}\right\} \mathrm{Nd}(\mu-\mathrm{Cl})_{2} \mathrm{Li}-(\mathrm{THF})_{2}\right] \underline{\mathbf{1 8 b}}$ and $\left[\left\{\mathrm{Me}_{2} \mathrm{Si}\left(\eta^{5}-2,4-\left(\mathrm{SiMe}_{3}\right)_{2} \mathrm{C}_{5} \mathrm{H}_{2}\right)\left(\eta^{5}-3,4-\right.\right.\right.$ $\left.\left.\left.\left(\mathrm{SiMe}_{3}\right)_{2} \mathrm{C}_{5} \mathrm{H}_{2}\right)\right\} \mathrm{Nd}(\mu-\mathrm{Cl})_{2} \mathrm{Li}-(\mathrm{THF})_{2}\right] \underline{\mathbf{1 8 c}}$, in combination with a dialkylmagnesium cocatalyst for the polymerization of 1-octene (Scheme 13). ${ }^{45}$ Even if molecular weights decreased in the presence of higher amounts of dialkylmagnesium, the experimental molecular weights of the oligooctenes obtained are lower than the theoretical ones calculated assuming two growing chains per magnesium atom, suggesting significant $\beta \mathrm{H}$ abstraction. This assumption was confirmed by NMR analyses. 


\subsection{Styrene}

The most commonly used CTA for styrene CCTP are based on magnesium ${ }^{4 ; 46-52}$ and aluminum alkyls. ${ }^{53-54}$ One of the problems associated with styrene CCTP is the need for high temperatures that leads to the occurrence of radical polymerization. For example, the chlorolanthanidocene $\underline{\mathbf{1 b}}$ / dialkyl magnesium system allowed when applied to styrene the simultaneous occurrence of radical and coordination polymerization $\left(\mathrm{T}=105^{\circ} \mathrm{C}\right.$, Scheme 14$) .{ }^{46}$ In the presence of $n$-butylethylmagnesium or $n, s$-dibutylmagnesium alone, styrene polymerization proceeded via thermal selfinitiation, but was accompanied by a reversible transfer to dialkylmagnesium to yield in turn oligostyrylmagnesium species. MALDI-TOF (Matrix Assisted Laser Desorption/Ionization - Time of Flight mass spectroscopy) analyses indicated the presence of ethyl and butyl headgroups, consistent with the transfer process.

When combined with dialkylmagnesium, cerium (IV) alkoxides $\underline{\mathbf{1 9}}$ and $\underline{\mathbf{2 0}}$ (Figure 3) oligomerized styrene at high temperature $\left(105^{\circ} \mathrm{C}\right)$, providing chain transfer reactions to magnesium as evidenced by the decrease of molecular weights with the increase of $\mathrm{Mg} / \mathrm{Ce}$ ratios. ${ }^{47}$ Transmetalation efficiencies were in the range $32-79 \%$ and the authors proposed the existence of two concomitant pathways which enable styrene polymerization: (a) radical polymerization initiated by free radicals generated from the redox-active metal precursors (being this the major pathway) and (b) coordination / insertion polymerization based on in situ produced $\mathrm{Ce}(\mathrm{III})$ - and/or $\mathrm{Ce}(\mathrm{IV})$-alkyl species.

Using systems based on lanthanide trisborohydride complexes $\underline{\mathbf{2 1}}$ the problem associated with high temperatures could be overcome since these catalysts are active in mild conditions for reactions times where the auto-initiated radical polymerization of styrene is nearly inexistant. ${ }^{48,52} \mathrm{Ln}\left(\mathrm{BH}_{4}\right)_{3}(\mathrm{THF})_{3}(\mathrm{Ln}=\mathrm{Nd}$, La) afforded the transfer 
polymerization of styrene with substantial transfer efficiencies and good yields, but with the simultaneous occurrence of $\beta \mathrm{H}$ abstraction (Scheme 15). The occurrence of this undesirable termination pathway could further be overcome with a pentamethylcyclopentadienyl ligand in the coordination sphere of the rare earth metal. The electron donating ability of this latter ligand leads to a higher electron density around the metal centre that may disfavor agostic interactions. This may lead to less $\beta \mathrm{H}$ abstraction. The catalytic systems $\mathrm{Cp}^{*} \operatorname{Ln}\left(\mathrm{BH}_{4}\right)_{2}(\mathrm{THF})_{2} \underline{\mathbf{2 2}}$ / $n$-butylethylmagnesium (Ln $=\mathrm{Nd}, \mathrm{La}$ ) afforded, in this frame, the first example of a polystyrene $\mathrm{CCG}^{4,52}$ (Scheme 16) by allowing (i) all alkyl groups to be involved in the chain transfer and (ii) a living character as evidenced by a continued chain growth after a second addition of monomer. The reaction was further found to be $85 \%$ syndioselective. Based on steric considerations, an analogy was drawn between lanthanidocene catalyzed polyethylene chain growth on magnesium and half-lanthanidocene catalyzed polystyrene chain growth on magnesium considering an interaction between the rare earth centre and the aromatic ring (Scheme 17). It was also evidenced that lanthanum based complexes lead to less $\beta \mathrm{H}$ abstraction than neodymium based complexes in the course of the polymerization of styrene. This may be attributed to steric considerations but also to the lower Lewis acidity of lanthanum vs. neodymium that may lead to a lesser extent of agostic interactions, and thus to a decrease of $\beta \mathrm{H}$ abstraction. The polymerization of styrene using $\mathrm{LaCl}_{3}(\mathrm{THF})_{3}$ in combination with magnesium dialkyl was found to occur without $\beta \mathrm{H}$ abstraction in the presence of 1 to several equiv. magnesium dialkyl, and the quantitative transfer efficiency observed allowed to conclude that a CCG reaction is occurring using the latter combination. Other CCTPs of styrene reported in the literature were found to occur with lower chain transfer efficiencies. Syndioselective polystyrene CCTP to magnesium was reported by Carpentier et al. using an ansa- 
chloroneodymocene dimer, $\left[\left(\mathrm{Cp}-\mathrm{CMe}_{2}-\mathrm{Flu}\right) \mathrm{Nd}(\mu-\mathrm{Cl})\right]_{2} \underline{\mathbf{2 3}}$, combined to di- $n$-butyl and diallylmagnesium at $60{ }^{\circ} \mathrm{C}$ (1-100 equiv. vs. Nd). ${ }^{49}$ Substantial decrease of the number average molecular weight with the amount of magnesium compound is observed, with yields of isolated polymers lower than $20 \%$. The experimental values of molecular weights were found to be systematically higher than those calculated, reflecting a modest initiation together with a modest transfer efficiency (1-7\%). The latter could be substantially increased using the neutral allyl neodymocene $\underline{\mathbf{2 4}}$, highlighting interestingly a highly syndioselective and efficient CCTP (Scheme 18). Carpentier and coworkers also reported the first isoselective CCTP of styrene using the bis-indenyl yttrium pre-catalyst $\underline{\mathbf{2 5}}$ combined to magnesium dialkyl, with dispersity in the range 1.4-1.8 and high transfer efficiency in certain cases (Scheme 18). ${ }^{50-51}$ It is noteworthy that the growth of more than 200 macromolecular chains per yttrium centre can be achieved.

Catalysts based on titanium leading to the syndiospecific polymerization of styrene were also been reported for $\mathrm{CCTP} .{ }^{53} \mathrm{Using} \mathrm{Ti}(\mathrm{OEt})_{4} \underline{\mathbf{2 6}}$ and $\mathrm{CpTiCl}_{3} \underline{\mathbf{2 7}}$ with MAO combined with $\mathrm{AlMe}_{3}$, the weight average molecular weight decreased almost linearly with increasing amounts of the CTA. A very sharp decrease of the molecular weights was in turn observed by the addition of even moderate amounts of $\mathrm{Al}^{\mathrm{i}} \mathrm{Bu}_{3}$. This was explained by the propensity of the CTA to prevent from $\beta$-hydride abstraction. A ${ }^{13} \mathrm{C}$ NMR analysis of the polymer end-groups showed that the occurrence of $\beta$-hydride abstraction tends to decrease with the amount of $\mathrm{AlMe}_{3}$ introduced, and disappeared when $\mathrm{Al}^{\mathrm{i}} \mathrm{Bu}_{3}$ was used as a chain transfer agent. Chain termination occurred exclusively by transfer to the aluminum centre in the latter case (Scheme 19). The transfer efficiency can unfortunately not be calculated from the reported values. It is noteworthy that this study reported the first example of a highly syndiospecific CCTP of styrene. 
Syndiospecific styrene CCTP was also reported using $\mathrm{Cp} * \mathrm{Ti}(\mathrm{OMe})_{3} \underline{\mathbf{2 8}}$ / $\left[\mathrm{C}_{6} \mathrm{H}_{5} \mathrm{~N}\left(\mathrm{CH}_{3}\right)_{2} \mathrm{H}\right]\left[\mathrm{B}\left(\mathrm{C}_{6} \mathrm{~F}_{5}\right)_{4}\right]$ combined to triethyl-, tri- $n$-propyl and triisobutylaluminum. ${ }^{54}$ Substantial decreases of the weight average molecular weight with the amount of trialkylaluminium were reported. The transfer efficiency could be classified in the following order: $\mathrm{AlEt}_{3}>\mathrm{Al} n-\mathrm{Pr}_{3}>\mathrm{Al}^{i} \mathrm{Bu}_{3}$. However, it is not possible to quantify the amount of aluminum end-capped syndiotactic polystyrene chains from the reported data.

\subsection{Conjugated dienes}

CCTP of conjugated dienes was mainly reported to be $1,4-$ cis stereoselective. ${ }^{55-61}$ The transmetalation of a growing polydiene chain could be accompanied by a decrease of the 1,4-cis selectivity of the reaction. Rare earth trichloride adducts and versatate were among the most studied precatalysts in the presence of aluminum and zinc based chain transfer agents. The chain transfer efficiency was only moderate with these systems $(2-14 \%)$. A major drawback was the simultaneous change of polymerization rates, as observed by Friebe et al. for the ternary system neodymium versatate $\underline{\mathbf{2 9}}$ (Figure 4) / ethylaluminum sesquichloride / aluminum alkyl. ${ }^{56,58}$ This system allowed a reversible exchange of the living polybutadiene chains between neodymium and aluminum, however, the polymerization rate was highly decreased in transfer conditions.

The impact of aluminum alkyl on the polymerization kinetics and on the control of molecular weights was further studied using di-isobutyl aluminumhydride and triisobutylaluminum $\left(\mathrm{Al}^{i} \mathrm{Bu}_{3}\right) .{ }^{58}$ The difference between these two aluminum compounds in terms of transfer efficiency was significant. $\mathrm{AlH}^{i} \mathrm{Bu}_{2}$ was eight times more effective than $\mathrm{Al}^{i} \mathrm{Bu}_{3}$, and the substitution probability of $\mathrm{Al}-\mathrm{H}$ was approximately 22-fold higher 
that of Al-isobutyl (transfer efficiency for $\mathrm{AlH}^{i} \mathrm{Bu}_{2}=10-14 \%$ and for $\mathrm{Al}^{i} \mathrm{Bu}_{3}=1-2 \%$ ). This great difference reflects the importance of Al-based cocatalysts with Al-H moieties. The differences between their respective reaction rates and the equilibrium positions are schematically presented in Scheme 20. Although $\mathrm{AlH}^{i} \mathrm{Bu}_{2}$ exhibited higher transfer efficiency than $\mathrm{Al}^{i} \mathrm{Bu}_{3}$, only one third of the total amount of $\mathrm{AlH}^{i} \mathrm{Bu}_{2}$ was involved in the molecular weight control. This feature was further explained by the possible aggregation of $\mathrm{AlH}^{i} \mathrm{Bu}_{2}$, which could form trimers.

Diethyl zinc was added to the previous ternary system (neodymium versatate / ethylaluminum sesquichloride / $\left.\mathrm{AlH}^{i} \mathrm{Bu}_{2}\right) .{ }^{60}$ On the one hand, the addition of $\mathrm{ZnEt}_{2}$ did not change the living nature of the polymerization and had limited impact on the polymerization rate. On the other hand, $\mathrm{ZnEt}_{2}$ did not only reduce the molecular weight, but lead also to a reduction of the dispersities. However, a decrease of the 1,4-cis content was observed, as it was already observed for $\mathrm{AlH}^{i} \mathrm{Bu}_{2}$, from 94 to $84 \%$ with increasing quantities of diethylzinc up to 30 equiv. vs. Nd in the presence of 20 equiv. $\mathrm{AlH}^{i} \mathrm{Bu}_{2}$. The influence of $\mathrm{Al}^{i} \mathrm{Bu}_{3}$ on the stereoselectivity was unfortunately not reported. In terms of molar mass control efficiencies, one can establish the following trend: $\mathrm{AlH}^{i} \mathrm{Bu}_{2}>\mathrm{ZnEt}_{2}>\mathrm{Al}^{i} \mathrm{Bu}_{3}$.

The neodymium versatate $\underline{\mathbf{2 9}}$ was also recently used in combination with dimethylchlorosilane $\left(\mathrm{Me}_{2} \mathrm{SiCl}_{2}\right)$ and di-isobutylaluminum hydride for the CCTP of isoprene. ${ }^{62}$ The authors found out that only one third of the hydride moieties participates in the formation of the new polymer chains at a $[\mathrm{Al}-\mathrm{H}] /[\mathrm{Nd}]=20$, as already observed by Friebe. ${ }^{58}$ Since termination reactions are negligible using this system, a chain-end functionalization was performed by introducing carbon dioxide to the polymerization solution. After treatment of the resulting polymer, FTIR spectra showed the presence of the carboxylic acid, but quantification informations were not reported. 
Chain transfer between neodymium and aluminum in the course of the polymerization of isoprene was also reported using $\underline{\mathbf{3 0}}$ in combination with $\mathrm{Al}^{i} \mathrm{Bu}_{3} /\left[\mathrm{Ph}_{3} \mathrm{C}\right]\left[\mathrm{B}\left(\mathrm{C}_{6} \mathrm{~F}_{5}\right)_{4}\right]$. This resulted in a broadening of the molecular weight distribution of the resulting 1,4-cis enriched polyisoprene. ${ }^{63}$ A ternary catalytic system composed of $\mathrm{Nd}(\mathrm{O} i-\mathrm{Pr})_{3} \underline{\text { 31a }},\left[\mathrm{HNMe}_{2} \mathrm{Ph}\right]^{+}\left[\mathrm{B}\left(\mathrm{C}_{6} \mathrm{~F}_{5}\right)_{4}\right]^{-}$and $\mathrm{Al}^{i} \mathrm{Bu}_{3}$ also showed a decrease of molecular weights and a broadening of the dispersity in the presence of larger amounts of aluminum, together with a modest transfer efficiency $(2-3 \%) .{ }^{64}$ The polymers were highly 1,4-cis with dispersities between 2-3. The optimal composition for this catalytic system was found to be $[$ borate $] /[\mathrm{Nd}]=1$ and $[\mathrm{Al}] /[\mathrm{Nd}]=30$. Chain transfer between neodymium and aluminum was also observed using $\mathrm{Nd}(2,6$-di-tertbutyl-OC $\left.{ }_{6} \mathrm{H}_{3}\right)_{3} \underline{\mathbf{3 2}}$ combined with various amount of MAO and MMAO, yielding nonstereoregular polyisoprenes. ${ }^{65}$ The neodymium isopropoxyde $\underline{\text { 31a }}$ was also used in combination with $\mathrm{Me}_{2} \mathrm{SiCl}_{2}$ and di-isobutyl aluminum hydride for the CCTP of isoprene. ${ }^{66}$ Quantitative yields together with dispersities in the range 1.2-1.5 were reported. Transfer efficiencies up to $12-14 \%$ were obtained, together with molecular weight up to $30000 \mathrm{~g} / \mathrm{mol}$. It should be noted here that the molecular weight values of polyisoprene have to be divided by a factor of $c a$. 2 to get the true $\mathrm{Mn}$, as polystyrene standards were used for the measurements of the $\mathrm{Mn}$ by size exclusion chromatography. ${ }^{67-69}$ This leads to transfer efficiencies as high as $24-28 \%$, which are among the highest reported in the literature using aluminium based chain transfer agents. The living character of the CCTP was confirmed by a second isoprene feed, and the formation of polyisoprene-block-poly( $\varepsilon$-caprolactone) copolymers.

The cationic borohydrido lanthanide complex $\left[\mathrm{Nd}\left(\mathrm{BH}_{4}\right)_{2}(\mathrm{THF})_{5}\right]^{+}\left[\mathrm{B}\left(\mathrm{C}_{6} \mathrm{~F}_{5}\right)_{4}\right]^{-}$, was found to be highly active towards isoprene polymerization upon activation with $\mathrm{Al}^{i} \mathrm{Bu}_{3} .{ }^{70}$ The in situ prepared ternary system $\mathrm{Nd}\left(\mathrm{BH}_{4}\right)_{3}(\mathrm{THF})_{3} \quad \underline{\mathbf{2 1}} /$ 
$\left[\mathrm{HNMe}_{2} \mathrm{Ph}\right]\left[\mathrm{B}\left(\mathrm{C}_{6} \mathrm{~F}_{5}\right)_{4}\right] / \mathrm{Al}^{i} \mathrm{Bu}_{3}$ was less active but affords a higher cis-selectivity and a better control in terms of macromolecular data (Scheme 21). The amount of cocatalyst was found to be directly related to the selectivity and the molecular weight control. In the presence of a large excess of cocatalyst, lower molecular weights were obtained, showing transfer reactions between $\mathrm{Nd}$ and $\mathrm{Al}$ and confirming the role of $\mathrm{Al}$ as transfer agent; however the transfer efficiencies were quite low $(4-6 \%)$. The dispersity values remained narrow indicating a rapid exchange between $\mathrm{Al}$ and $\mathrm{Nd}$, but with loss of both selectivity and activity.

Isoprene CCTP was also reported using aminophenyl functionalized cyclopentadienyl rare-earth metal allyl mediated cationic systems $\left(\left(\mathrm{C}_{5} \mathrm{Me}_{4}-\mathrm{C}_{6} \mathrm{H}_{4}-\mathrm{O}^{-}\right.\right.$ $\left.\left.\mathrm{NMe}_{2}\right) \mathrm{Gd}\left(\eta^{3}-\mathrm{C}_{3} \mathrm{H}_{5}\right)_{2}\right) \underline{\mathbf{3 3}}$ by Hou, Cui et al. ${ }^{71}$ The obtained polymers were found to be highly 1,4-cis regular, and a transmetalation between gadolinium and aluminum was observed with transfer efficiencies between 6-8\%.

If CCTP of 1,3 dienes is well documented for 1,4-cis stereoselective reactions, few examples were reported in the case of 1,4-trans stereoselectivity. A brief description of 1,4-trans stereoselective chain transfer oligomerization of butadiene was reported using $\mathrm{Nd}(\mathrm{O}-2,6-\mathrm{t}-\mathrm{Bu} 2-4-\mathrm{Me}-\mathrm{Ph})_{3}$ combined to dihexylmagnesium $(\mathrm{Mn} 1100$ $\mathrm{g} / \mathrm{mol}$, 5 equiv. CTA). ${ }^{72}$ The first 1,4-trans stereospecific CCTP of isoprene was reported recently. ${ }^{69,73} \mathrm{~A}$ series of lanthanum and neodymium complexes $\left(\operatorname{Ln}\left(\mathrm{BH}_{4}\right)_{3}(\mathrm{THF})_{3} \underline{\mathbf{2 1}}, \mathrm{Cp}^{*} \operatorname{Ln}\left(\mathrm{BH}_{4}\right)_{2}(\mathrm{THF})_{2} \underline{\mathbf{2 2}}, \mathrm{LaCl}_{3}(\mathrm{THF})_{3}, \mathrm{NdCl}_{3}(\mathrm{THF})_{3}, \mathrm{Ln}\left(\mathrm{O}^{i} \mathrm{Pr}\right)_{3}\right.$ $\underline{\mathbf{3 1}}$ and $\left.\mathrm{Nd}\left(\mathrm{OC}_{6} \mathrm{H}_{3}{ }^{t} \mathrm{Bu}_{2}-2,6\right)_{3}\right)$ 2ㅡ $)$ were assessed for the CCTP of isoprene in combination with $n$-butylethylmagnesium. ${ }^{69}$ Among these catalysts, rare earth borohydrides were found to be the most efficient for isoprene CCTP. Lanthanum and neodymium trisborohydrides led to chain transfer efficiencies in the range $50-60 \%$, while the half-lanthanidocenes led to chain transfer efficiencies close to $100 \%$, 
highlighting the first example of a polyisoprene CCG (Scheme 22a). The polymerization activity was found to be higher for lanthanum vs. neodymium based catalysts. Lanthanum and neodymium chloride, isopropoxide and aryloxide were found to be poorly active under the same experimental conditions. One feature of these CCTP reactions is the fact that transmetalation was accompanied by a change in the selectivity of the reaction. Using increasing quantities of magnesium dialkyl, a gradual decrease of the 1,4-trans stereoselectivity of the reaction was observed at the benefit of 3,4selectivity. This is particularly interesting regarding the work that would be required for the synthesis of the different catalysts able to lead to the same array of polyisoprenic materials by classical coordination/insertion polymerization. The higher quantities of 3,4 enchainments was proposed to be attributed to (i) steric hindrance induced by the presence of dialkyl or di-isoprenyl magnesium in excess, hindering the $\eta^{4}$ coordination mode of isoprene and leading to a $\eta^{2}$ coordination mode of the monomer and/or (ii) the propensity of magnesium-isoprene adducts to oligomerize isoprene in a 3,4-selective process. ${ }^{74}$ Inspired by the earlier work of Yasuda, ${ }^{74}$ it was shown that $n$ BuMgEt was able to oligomerize isoprene without any additional transition metal based catalyst. The isoprenyl magnesium moieties formed in the course of a CCTP can thus no longer be considered as a dormant species, as usually accepted for a chain transfer agent metal polymeryl moieties in the course of a CCTP. The reaction was thus considered to operate under a similar process to chain shuttling polymerization, however without the intervention of a third chain shuttling agent component. This is represented in Scheme 23. The overall approach was extended to the CCTP of a natural conjugated diene from the terpene family, myrcene, using $\mathrm{Nd}\left(\mathrm{BH}_{4}\right)_{3}(\mathrm{THF})_{3}$ in combination with $n$ butylethylmagnesium. ${ }^{75}$ Similar trends were observed, i.e. a high transfer efficiency together with a modification of the regioselectivity of the polymerization of myrcene 
from 1,4-cis to 3,4. n-Butylethylmagnesium was also found to oligomerize myrcene in a 3,4 regioselective manner over long reaction times.

With the objective to preserve the 1,4-trans stereoselectivity along the chain transfer polymerization of isoprene, several CTAs based on aluminum, zinc and boron were assessed in combination with the active species derived from $\mathrm{Cp} * \mathrm{La}\left(\mathrm{BH}_{4}\right)_{2}(\mathrm{THF})_{2}$ 22b / 1 equiv. $n$ BuMgEt that lead to the 1,4-trans stereoselectivity. Boron and zinc alkyls were found to be inefficient for the chain transfer polymerization. $\mathrm{AlEt}_{3}$ and $\mathrm{Al}^{i} \mathrm{Bu}_{3}$ lead to a transmetalation of the growing polymer chain, with efficiencies in the range 22-26\% per aluminum atom. A similar behavior was observed using $\mathrm{AlH}^{i} \mathrm{Bu}_{2}$, with an efficiency of $19 \%$. The catalyst was found to be poorly active using $\mathrm{AlEt}_{2} \mathrm{Cl}$. It is noteworthy that using $\mathrm{AlEt}_{3}, \mathrm{Al}^{i} \mathrm{Bu}_{3}$ and $\mathrm{AlH}^{i} \mathrm{Bu}_{2}$ the polymerization remained 1,4trans stereospecific (96-98\%, Scheme 22b), highlighting the first example of a 1,4-trans stereospecific CCTP of isoprene. It was proposed that the less pronounced ionic character of the metal-carbon bond in alkylaluminum vs. alkylmagnesium compounds does not allow to disturb the $\mathrm{La}-\mathrm{Mg}$ bimetallic active species leading to the 1,4-trans stereoselectivity.

The $\quad r a c-\left[\left\{\mathrm{Me}_{2} \mathrm{C}(\mathrm{Ind})_{2}\right\} \mathrm{Y}\left(1,3-\left(\mathrm{SiMe}_{3}\right)_{2}-\mathrm{C}_{3} \mathrm{H}_{3}\right)\right] \underline{\mathbf{2 5}}$ catalyst was used by Carpentier et al. to polymerize isoprene, either as a single-site component catalyst or in combination with a CTA. ${ }^{77}$ Using $\mathrm{ZnEt}_{2}$ or $\mathrm{Al}^{i} \mathrm{Bu}_{3}$, the CCTP of isoprene was achieved while maintaining a 1,4-trans stereoselectivity (87-90\%). When $\mathrm{Mg}^{n} \mathrm{Bu}_{2}$ was used, the 1,4-trans stereoselectivity gradually decreased with increasing quantities of this CTA at the expense of a 3,4-regioselectivity (1,4-trans: 53-78\%), as already observed in the aforementioned studies.

Chain transfer within the course of a 3,4-selective polymerization of isoprene is rare. Modest chain transfer efficiencies were reported using nonmetallocene rare earth 
metal bis(alkyl) by Cui et al. ${ }^{76}$ The scandium complex $\left[\left(\mathrm{NPN}^{\mathrm{Ph}}\right) \mathrm{Sc}-\left(\mathrm{CH}_{2} \mathrm{SiMe}_{3}\right)_{2}(\mathrm{THF})\right]$ $\left(\mathrm{NPN}^{\mathrm{Ph}}: \mathrm{N}(\mathrm{Ph}) \mathrm{PPh}_{2}=\mathrm{NC}_{6} \mathrm{H}_{2} \mathrm{Me}_{3}-2,4,6\right) \underline{\mathbf{3 4}}$ in combination with $\left[\mathrm{PhNHMe}_{2}\right]\left[\mathrm{B}\left(\mathrm{C}_{6} \mathrm{~F}_{5}\right)_{4}\right]$ and $\mathrm{Al}^{i} \mathrm{Bu}_{3}$ provides high activity and 3,4-selectivity towards isoprene polymerization (up to $94.7 \%$ at $-40{ }^{\circ} \mathrm{C}$, Scheme 24 ). Interestingly, when increasing the $[\mathrm{Al}] /[\mathrm{Sc}]$ ratio, a higher activity was observed, followed by a decrease of the molecular weights suggesting the occurrence of chain transfer reactions in the course of polymerization.

\section{Statistical Coordinative Chain Transfer co-Polymerizations (CCTcoP)}

In a statistical Coordinative Chain Transfer co-Polymerization (CCTcoP) one catalyst and one chain transfer agent are used to afford a statistical copolymer (Scheme 25). Chain transfer reactions in the course of copolymerizations have been assessed mainly for ethylene-based materials using transition metal catalysts in combination with alkylaluminum or alkylzinc CTAs.

The first synthesis of a poly(ethylene-co-comonomer) using the CCTP approach is reported for the copolymerization of ethylene with allylbenzene using racethylenebis(indenyl) zirconium dichloride $\underline{\mathbf{1 2 a}}$ (Figure 2)/ MAO at $80^{\circ} \mathrm{C}$ in toluene at a constant ethylene pressure of 1.2 bar. $^{78}$ The comonomer incorporation could be increased until $20 \%$ changing the initial feed of allylbenzene. On the basis of end group analysis by NMR and the decrease of molecular weight of copolymers with the introduction of increasing amounts of trimethylaluminum, it was revealed that chain transfer to aluminum was the preferred chain transfer reaction during the copolymerization (dispersity $1.6-4.1$ ). Chain termination through aluminum transfer was suggested to be induced by the allylbenzene unit incorporated in the propagating chain end. The introduction of increasing amounts of $\mathrm{AlMe}_{3}$ in the reaction medium did 
not induce substantial changes of the allylbenzene incorporation in the copolymer. A complementary study using catalysts $\underline{\mathbf{3 5}}$ (Figure 5) and $\underline{\mathbf{1 1}}$ (Figure 1) has also been performed in order to infer about possible mechanisms. ${ }^{79}$ The catalysts structures were directly related to their ability to undergo $\beta-\mathrm{H}$ abstraction during the copolymerization. $\beta$ - $\mathrm{H}$ abstraction was observed using $\mathrm{Cp}_{2} \mathrm{ZrCl}_{2}$ and $(n-\mathrm{BuCp})_{2} \mathrm{ZrCl}_{2}$, while using (2MeInd) ${ }_{2} \mathrm{ZrCl}_{2}$ and $\mathrm{Cp}^{*}{ }_{2} \mathrm{ZrCl}_{2}$ chain transfer to aluminum was the preferred mechanism. This behaviour was rationalized in terms of the chain conformation for $\beta$-agostic interaction which is believed by many authors to stabilize the metal centre and favor $\beta$ H abstraction. ${ }^{80-83}$

CCTcoP of ethylene $\left(60{ }^{\circ} \mathrm{C}, 1.5\right.$ bar $)$ and propylene $\left(50{ }^{\circ} \mathrm{C}, 1.5\right.$ bar $)$ with longchain amide and amine functional alkenes (Scheme 26) was assessed in the presence of the rac-ethylenebis(1-indenyl)zirconium dichloride $\underline{\mathbf{1 2 a}}$ and rac-dimethylsilylbis(2methylindenyl)zirconium dichloride) $\underline{\mathbf{1 3 b}}$ zirconocenes / MAO systems. ${ }^{84}$ The incorporation of the amide comonomer changed slightly with the amount of cocatalyst, remaining in the $0.24-1.3 \mathrm{~mol} \%$ range with ethylene and in the $0.04-0.96 \mathrm{~mol} \%$ range with propylene. The predominant end groups observed in ${ }^{13} \mathrm{C}$ NMR spectra were saturated linear and isobutyl chain ends for ethylene and propylene copolymers, respectively, showing the chain transfer to the aluminum centre.

More hindered zirconocenes complexes, rac-dimethylsilylbis(2-methyl-4phenyl-1-indenyl) zirconium dichloride $\underline{\mathbf{3 6 a}}$ and rac-dimethylsilylbis(2-isopropyl-4[3,5-dimethylphenyl] indenyl)zirconium dichloride) $\underline{\mathbf{3 6} \mathbf{b}}$ were used for the CCTcoP of ethylene with propylene in combination with MAO $\left(70^{\circ} \mathrm{C}, 1.5-5.0\right.$ bar $) .{ }^{85}$ The most common termination pathway was chain transfer to aluminum for both catalysts, with however the occurrence of other chain termination reactions. Using $\underline{\mathbf{3 6} \mathbf{a}}, \beta \mathrm{H}$ transfer to 
the monomer and to the metal were observed, while using the more hindered $\underline{\mathbf{3 6} \mathbf{b}}$ leads to the occurrence of $\beta \mathrm{H}$ and $\beta$-methyl transfer to the metal.

The CCTcoP of ethylene with 1-alkenes was reported using pyridylamide Hf $\underline{\mathbf{g}}$ and bis(phenoxy- imine) $\operatorname{Zr} \underline{37}$ catalysts used for chain shuttling copolymerization. ${ }^{3 ; 22-23}$ It is noteworthy that more than 200 growing chains per transition metal are observed in the presence of excess $\mathrm{ZnEt}_{2}$ as chain transfer agent for the former, and more than 2000 for the latter. $\underline{\mathbf{3 7}}$ combined to $\mathrm{ZnEt}_{2}$ led furthermore to linear $\mathrm{Mn} v s$. yield plots indicative of CCTP. Ethylene/1-hexene copolymerization experiments conducted using $\underline{9}$ and $\mathrm{AlOct}_{3}$ as $\mathrm{CTA}^{23}$ led to $13-16 \%$ 1-hexene in the copolymer. They were quenched with $\mathrm{D}_{2} \mathrm{O}$ after varied reaction times. A detailed deuterium labelling study revealed that chain transfer to aluminum is the dominant termination mechanism under these conditions. Interestingly, ${ }^{2} \mathrm{H}$ and ${ }^{13} \mathrm{C}$ NMR experiments indicated that chain transfer from $\underline{9}$ to $\mathrm{AlOct}_{3}$ occurs significantly faster after an ethylene insertion than after a hexene insertion.

\section{Using $\{\mathrm{Cp} * \mathrm{Hf}(\mathrm{Me})[\mathrm{N}(\mathrm{Et}) \mathrm{C}(\mathrm{Me}) \mathrm{N}(\mathrm{Et})]\}\left[\mathrm{B}\left(\mathrm{C}_{6} \mathrm{~F}_{5}\right)_{4}\right] \quad\left(\mathrm{Cp}^{*}=\eta^{5}-\mathrm{C}_{5} \mathrm{Me}_{5}\right)$ or} $\{\mathrm{Cp} * \mathrm{Hf}(\mathrm{Me})-[\mathrm{N}(\mathrm{Et}) \mathrm{C}(\mathrm{Me}) \mathrm{N}(\mathrm{Et})]\}\left[\mathrm{B}\left(\mathrm{C}_{6} \mathrm{~F}_{5}\right)_{3} \mathrm{Me}\right] \underline{\mathbf{8}}$ in combination with diethylzinc affords the CCTcoP of ethylene with $\alpha$-olefins (1-hexene and 1-octene) and $\alpha, \omega$ nonconjugated dienes $\left(1,5\right.$-hexadiene) in toluene at $50{ }^{\circ} \mathrm{C} .{ }^{30}$ The decrease of molecular weights with increasing quantities of chain transfer agent evidenced the chain transfer reactions. The ethylene content in the copolymer remains unchanged, around $82-84 \%$.

Polymer chain transfer in the course of norbornene / ethylene copolymerizations has been reported using the catalytic systems $\mathrm{Me}_{2} \mathrm{C}(\mathrm{Ind})(\mathrm{Cp}) \mathrm{ZrCl}_{2} \underline{\mathbf{3 8}}$ / $\mathrm{MAO}$ or rac$\mathrm{C}_{2} \mathrm{H}_{4}\left(2-{ }^{t} \mathrm{BuMe}_{2} \mathrm{SiO}-\mathrm{Ind}\right)_{2} \mathrm{ZrCl}_{2} \underline{\mathbf{1 2 b}} / \mathrm{MAO}$ in combination with aluminum or zinc alkyls $\left(\mathrm{AlR}_{3}\right.$ or $\mathrm{ZnR}_{2}, \mathrm{R}=\mathrm{Me}$ or $\left.\mathrm{Et}\right){ }^{86}$ The resulting decrease of the molecular weights of norbornene-ethylene copolymers indicates that the growing polymeric chains are able to 
transfer from the $\mathrm{Zr}$ catalyst to the $\mathrm{Al}$ or $\mathrm{Zn}$ centres by alkyl-polymeryl exchange. It is noteworthy that the norbornene content is increased by a factor of $c a .4$ upon addition of modest amounts of chain transfer agent, but decreased to about one-third of its initial value when the chain transfer agent was added in larger excess. The use of $\mathrm{Al}^{i} \mathrm{Bu}_{3}$ as potential chain transfer agent led in turn to an increase of the molecular weight. The mononuclear, tricoordinate geometry of $\mathrm{Al}^{i} \mathrm{Bu}_{3}$ enforced by its bulky alkyl ligands leads in the presence of trimethylaluminum to the formation of mixed species, which can form stable dimers with bridging Me groups (Scheme 27). ${ }^{87}$ These latter species are probably too bulky to react with catalytically active alkyl zirconocene cations, explaining the increase in molecular weight observed.

The changes in comonomer incorporation with the amount of chain transfer agent are particularly interesting, especially if a more controlled character can be obtained. The CCTcoP of isoprene, styrene and hexene was studied in this frame using lanthanide based pre-catalysts in combination with magnesium or aluminum alkyls (Scheme 28). ${ }^{73,88-89}$ A series of lanthanum and neodymium borohydrido complexes, comprising the trisborohydrides $\mathrm{Nd}\left(\mathrm{BH}_{4}\right)_{3}(\mathrm{THF})_{3}$ and $\mathrm{La}\left(\mathrm{BH}_{4}\right)_{3}(\mathrm{THF})_{3} \underline{\mathbf{2 1}}$ and the halflanthanidocenes $\mathrm{Cp}^{*} \mathrm{Nd}\left(\mathrm{BH}_{4}\right)_{2}(\mathrm{THF})_{2}$ and $\mathrm{Cp} * \mathrm{La}\left(\mathrm{BH}_{4}\right)_{2}(\mathrm{THF})_{2} \underline{\mathbf{2 2}}$, have been assessed for the CCTcoP of isoprene and styrene in the presence of butylethylmagnesium as CTA. ${ }^{73,88}$ For a monomer feed of 50 / 50 of styrene / isoprene, the amount of styrene inserted in the copolymer could be increased by a factor of 3.5 using 40 equiv. dialkylmagnesium vs. 1 equiv. in combination with $\underline{\mathbf{2 2}}$ and the content of 3,4 isoprene units increased from 2 to $55 \%$ at the expense of the 1,4 trans-selectivity. In addition, the number-average molecular weight of the copolymers decreased from 45200 to 3300 g.mol ${ }^{-1}$, highlighting the occurrence of a transmetalation of the growing polymer chains. The resulting molecular weights were monomodal in all cases and the dispersities were 
in the range 1.3 to 2.2 for a CCTP conducted in the presence of $2-40$ equiv $n \mathrm{BuMgEt}$. The comonomer content and the percentage of 3,4-enchainments increase gradually with the amount of CTA introduced for the half-lanthanidocenes $\underline{\mathbf{2 2}}$, highlighting attractive potential for microstructure control via CCTcoP. Concerning the metal nature, lanthanum affords narrower molecular weight distributions than neodymium, and the change in regioselectivity is less pronounced using the lanthanum trisborohydride $\underline{\mathbf{2 1 b}}$. It should also be noted that the half-lanthanidocenes $\underline{\mathbf{2 2}}$ afford higher activities under CCTcoP conditions than the trisborohydrides $\underline{\mathbf{2 1}}$.

Cp* $\mathrm{La}\left(\mathrm{BH}_{4}\right)_{2}(\mathrm{THF})_{2} / 1$ equiv. $n \mathrm{BuMgEt}$ in the presence of aluminum-based chain transfer agents allowed CCTcoP while maintaining the 1,4-trans stereoselectivity of the polymerization of isoprene (Scheme 28b). From the molecular weight values, it could be concluded that transfer reactions were occurring in the presence of aluminum alkyls, however, the transfer efficiency is again less significant than that observed using $n$ BuMgEt as CTA, as already observed in the case of isoprene CCTP. ${ }^{69}$ The styrene incorporation is increased by a factor of 1.5 in the presence of aluminium based CTA with respect to the run without CTA.

The increasing quantities of 3,4-enchainments observed when $n \mathrm{BuMgEt}$ is used in excess can be explained on the same basis as that observed in the course of the homopolymerization of isoprene, i.e. (i) steric hindrance induced by the presence of magnesium dialkyl or di-isoprenyl and (ii) the ability of magnesium alkyls to oligomerize isoprene in a 3,4-regioselective manner. (i) could lead to sterically hindered associated species where the $\eta^{4}$ coordination mode of isoprene would be inhibited, leading to a $\eta^{2}$ coordination mode of the monomer. This hypothesis has also been also advanced by other authors. ${ }^{90-94}$ (ii) implies in turn a chain-shuttling like copolymerization, as discussed previously. The 1,4-trans stereoselectivity observed in 
the presence of 1 equiv. $n$ BuMgEt and excess aluminum alkyls may be attributed to a lower ionic nature of the metal-carbon bond in aluminum alkyls vs. magnesium alkys. The former may indeed not be able to disrupt the 1,4-trans stereospecific bimetallic active species formed using 1 equiv. $n \mathrm{BuMgEt}$ in combination with the borohydrido rare earth.

The observed change in the apparent reactivity ratio and comonomer content in the copolymer in the presence of excess magnesium alkyls has been attributed to two alternative pathways:

i) A magnesium induced co-oligomerization of isoprene and styrene, leading to higher styrene content in the co-oligomer than that obtained using the $\mathrm{Cp} * \mathrm{La}\left(\mathrm{BH}_{4}\right)_{2}(\mathrm{THF})_{2} /$ nBuMgEt combination. ${ }^{88}$ Magnesium-based CTA may thus no longer be considered as dormant species, as observed for isoprene polymerizations. ${ }^{69}$ A kind of chain shuttling could be therefore operating between the rare earth and the magnesium-based catalysts in the course of the CCTP of isoprene and styrene, as represented in Scheme 29.

ii) A steric effect, considering the change in regioselectivity. In this case, styrene may be able to compete more efficiently during the coordination step to the lanthanide centre with a $\eta^{2}$ coordinated isoprene monomer $v s$. a $\eta^{4}$ coordinated isoprene monomer.

When aluminum alkyls are used as CTA the situation is different since aluminum species (i) are not able to co-oligomerize isoprene and styrene when used alone, ${ }^{88}$ and (ii) as observed and discussed for isoprene CCTP, they do not disturb in an important manner the Mg-La active species. As a consequence, the quantity of styrene inserted in the copolymer increases only slightly, and the 1,4-trans stereoselectivity of the polymerization of isoprene is maintained as CCTcoP is operating.

From these results, CCTcoP can be viewed as a new concept for the control over the comonomer apparent relative reactivity in the course of a statistical 
copolymerization, and as a consequence for the control of the microstructure of the resulting copolymers. The $\mathrm{Cp} * \mathrm{La}\left(\mathrm{BH}_{4}\right)_{2}(\mathrm{THF})_{2} \underline{\mathbf{2 2 b}}$ / $n$-butylethylmagnesium catalytic system was applied to the coordinative chain transfer polymerization of styrene and hexene (Scheme 28c). ${ }^{89}$ Copolymers with number-molecular weights up to $7600 \mathrm{~g} / \mathrm{mol}$ were obtained with dispersities around 1.4-1.5. The concept could be successfully extended, as chain transfer induced an increase of the amount of hexene inserted in the copolymer by a factor 3 when increasing the quantity of $n \mathrm{BuMgEt}$ from 1 equiv. (8.6\% hexene in the copolymer) to 10 equiv. (23.2\% hexene in the copolymer). Finally, it is also noteworthy that this study reports the first example of a rare-earth-mediated copolymerization of styrene and hexene.

Changes in apparent comonomer relative reactivity / incorporation with the nature of the chain transfer agent have also been reported in the course of the copolymerization of ethylene with polar monomers such as 10-undecen-1-ol, 5-hexen-1ol and 3-buten-1-ol using vanadium(III) catalysts bearing bidentate [N,O] ligands. ${ }^{95}$ Various alkylaluminums, such as $\mathrm{Al}^{i} \mathrm{Bu}_{3}, \mathrm{AlEt}_{3}, \mathrm{AlMe}_{3}$ and diethyl aluminum chloride were employed and the catalytic activity and monomer incorporation of the resulting copolymers were found to increase in the order: $\mathrm{Al}^{i} \mathrm{Bu}_{3}<\mathrm{AlEt}_{3}<\mathrm{AlMe}_{3}<$ diethyl aluminum chloride, in accordance with their increasing Lewis acidities. The activity of $\underline{39}$ (Figure 5) was gradually improved with higher Al/V molar ratios (1000-4000) while the comonomer incorporation was found to be independent of the catalyst concentration under these experimental conditions. Chain transfer to aluminum was observed as the molecular weights of the polymers decreased with increasing quantities of alkylaluminum compounds. Moreover, the ${ }^{13} \mathrm{C}$ NMR spectra did not show any traces of terminal vinyl signals. The highest incorporation of 10-undecene-1-ol (13.9 mol\%) was 
obtained for a functional $\alpha$-olefin charge of $0.5 \mathrm{~mol} / \mathrm{L}$; however, the activity of $\underline{\mathbf{3 9}}$ was considerably decreased.

From these works, it can be seen that CCTcoP enables a control over both the regioselectivity of the reaction and the comonomer apparent relative reactivity / composition of the copolymer and can be viewed as a simple and convenient tool for tuning the microstructure of statistical copolymers. 


\section{Chain Shuttling Polymerization (CSP)}

\subsection{CSP combined to Chain Walking Polymerization}

Besides statistical polymerizations, the chain shuttling approach was also applied to homopolymerizations. The synthesis of novel linear-hyperbranched multiblock polyethylene was reported via chain shuttling polymerization using $\underline{\mathbf{4 0}}$ (Figure 6) and $\underline{\mathbf{1 2} \mathbf{a}}$ in combination with $\mathrm{MAO}$ and $\mathrm{ZnEt}_{2}$ as a chain shuttling agent. ${ }^{96}$ The $\alpha$-diimine $\mathrm{Ni}(\mathrm{II})$ bromide catalyst $\underline{\mathbf{4 0}}$ produces branched polyethylene in the presence of MAO via chain walking polymerization, ${ }^{97}$ while the ansa-ethylenebis $\left(1-\eta^{5}\right.$ indenyl) Zr chloride catalyst $\underline{\mathbf{1 2 a}}$ produces linear polyethylene. Linear-hyperbranched multiblock polyethylene is formed as a result of the statistical exchange of the growing polymer chains between the two catalysts yielding polyethylene with different architecture via the chain shuttling agent, as represented in Scheme 30.

\subsection{CSP between enantiopure catalysts in a racemic mixture}

Busico and coworkers smartly extended the CSP concept to the synthesis of isotactic stereoblock polypropylene using a racemic mixture of $\underline{\mathbf{9}}$ in combination with MAO containing $\mathrm{AlMe}_{3}$ as the chain transfer agent. ${ }^{98}$ Isotactic stereoblock polypropylene (Scheme 31) is formed as a result of the statistical exchange of the growing polymer chains between the two active centres of opposite chirality via the chain shuttling agent. The chain shuttling was evidenced by the fact that, when single enantiomers were used, the stereoblock structure could not be observed. The synthesis of stereoblock polypropylene was also reported using $\mathrm{Zr}$ based catalysts ${ }^{99} \underline{\mathbf{1 6}}$ and $\underline{\mathbf{4 1}}$ leading to isotactic and syndiotactic polypropylene, respectively. 


\subsection{Chain shuttling copolymerizations}

In a cutting-edge study, Arriola and coworkers reported the straightforward synthesis of a new class of thermoplastic elastomers. ${ }^{3}$ Multi-block ethylene / 1-octene copolymers with sequential crystallizable (low 1-octene content) and non-crystallizable (low ethylene content) statistical copolymer segments were synthesized via chain shuttling copolymerization (Scheme 2). Such an original microstructure results from the simultaneous presence in the reactive medium of chains growing on two different catalysts and of a chain transfer or chain shuttling agent. Pyridylamide Hf () and bis(phenoxy- imine) $\mathrm{Zr}$ (프) complexes combined to $\mathrm{ZnEt}_{2}$ as chain shuttling agent have been selected for this purpose using high-throughput experiments. The comonomers reactivity ratios are different for the two catalysts, leading to ethylene-rich and 1-octene-rich segments respectively. The chains are able to growth in a sequential way on the two different catalysts via transfer to the chain shuttling agent. The transfer enables further control over the size and the relative amounts of the blocks are controlled by catalyst ratio, leading to shorter blocks as higher amounts of $\mathrm{ZnEt}_{2}$ are added in the reactive medium. ${ }^{100}$

The copolymers synthesized by Arriola et al. by chain shuttling are composed of crystallizable ethylene / 1-octene blocks with low 1-octene content and high melting temperature (hard blocks), and amorphous ethylene / 1-octene blocks with high 1-octene content and low glass transition temperature (soft blocks). Compared to statistical ethylene/1-octene copolymers, the new architecture leads to higher crystallization temperatures and rates, higher melting temperatures, and a better organized crystalline morphology, together with lower glass transition temperatures. ${ }^{100 ; 101}$ The differences between the copolymers obtained by chain shuttling and those obtained by classical 
statistical copolymerization become progressively more apparent as the total 1-octene content increases.

9 was also used for ethylene / 1-octene chain shuttling copolymerization in combination with $\mathrm{Zr}$ and $\mathrm{Hf}$ imine-amine catalysts $\mathbf{4 2 - 4 3}$ and $\mathrm{ZnEt}_{2}$ as chain shuttling agent. ${ }^{102}$ For a same feed, the nature of the catalyst enabled to tune the hard block, allowing one to make olefin block copolymers with control over melting point, crystallinity and solubility.

Ethylene / alkene chain shuttling copolymerization was further reported by Sita et al. using $\underline{\mathbf{8}}$ in combination with two different co-catalysts, the borate $\left[\mathrm{PhNHMe}_{2}\right]\left[\mathrm{B}\left(\mathrm{C}_{6} \mathrm{~F}_{5}\right)_{4}\right]$ and the borane $\mathrm{B}\left(\mathrm{C}_{6} \mathrm{~F}_{5}\right)_{3}$ and $\mathrm{ZnEt}_{2}$ as chain shuttling agent. ${ }^{103}$ The reactivity of ethylene and 1-hexene co-monomers vs. a tight and a loose ion pair generated in situ was found to be different, allowing a chain shuttling copolymerization similar to that reported by Arriola and coworkers ${ }^{3}$ with the use of a single transition metal based catalyst and three co-reagents. The inexistence of irreversible chain termination reactions together with a kinetic study allows to classify this copolymerization as living. Rytter et al. also advanced a possible ethylene / 1-hexene chain shuttling copolymerization using $\underline{\mathbf{1 1}}$ and $\underline{\mathbf{4}}$ combined to MAO in order to explain the presence of ethylene rich and 1-hexene rich blocks in the microstructure of the formed copolymers. ${ }^{104}$

The scandium based pre-catalysts $\underline{\mathbf{4 5 - 4 7}}$ were further used by Hou et al. for the styrene-isoprene chain shuttling copolymerization in combination with $\mathrm{Al}^{i} \mathrm{Bu}_{3}$ as chain shuttling agent. ${ }^{105}$ In contrast with the previous chain shuttling copolymerization, a multiblock microstructure of pure homopolymers was obtained (Scheme 32). The chain shuttling process induces this particular microstructure, as catalyst $\underline{\mathbf{4 5}}$ when used alone is known to copolymerize efficiently isoprene and styrene, leading to a mixture of 1,4- 
and 3,4- polyisoprene microstructure. ${ }^{106}$ Interestingly, the polymerization remains highly regioselective and stereoselective in chain shuttling conditions. Using $\underline{45}$ and $\underline{\mathbf{4 6}}$, the multiblock is composed of syndiotactic polystyrene and poly(1,4-cis isoprene), while with $\underline{\mathbf{4 5}}$ and $\underline{\mathbf{4 7}}$, poly(3,4-isoprene) blocks are obtained together with syndiotactic polystyrene. The styrene / butadiene / isoprene terpolymerization is finally reported, affording an unprecedented syndiotactic polystyrene / poly(1,4-cis isoprene) / poly(1,4cis butadiene) multiblock microstructure.

It is noteworthy that, in order to reach a multiblock microstructure via CSP, the transfer rate must not be too fast $v s$. propagation in order to allow sufficient chain growth on each of the catalysts. Fast transfer rates would in turn result in a homogeneous microstructure, as observed in isoprene chain shuttling-like polymerization promoted by $\mathrm{Cp} * \mathrm{Ln}\left(\mathrm{BH}_{4}\right)_{2}(\mathrm{THF})_{2}$ and $n$-butylethylmagnesium. ${ }^{73}$ Kinetic studies ${ }^{107}$ show further that a chain-shuttling rate constant that is too fast can alter the active-centre composition in a continuous stirring tank reactor, leading to different polymerization behaviour from that in the absence of the chain shuttling agent. It is also possible to observe a changing polymerization behaviour when a large amount of a chain shuttling agent allowing a moderate transfer rate is used.

\section{Concluding comments and perspectives}

CCTP can be considered as an approach of upmost importance considering the extension of the range of new polyolefin materials that can be obtained, using, many times, a single pre-catalyst. The versatility of chain transfer polymerization together with its ease of use relative to the synthetic effort required for the synthesis of different catalysts leading to the same pallet of materials or the difficulties encountered by other routes to reach an architecture control in polymerization makes this methodology an 
attractive and promising field for the future of coordination polymerization. In comparison with other controlled polymerization techniques such as anionic or controlled radical polymerizations, CCTP can additionally afford a stereoselective character to the polymerization, leading to stereoregular polymeric microstructures and architectures under living conditions. Moreover, CCTP affords not only control over the regio- and stereo-selectivity of polymerizations, but also on the comonomer apparent relative reactivity in the course of statistical copolymerizations and thus on the composition of statistical copolymers. The combination of two or more CTA is of particular interest in this regard, allowing to play on the active species in a subtle manner in certain cases. The search for suitable CTA combinations can result in interesting and unexpected applications in the field of CCTP. CTA combinations can however lead to bulky mixed species that are not prone to induce transmetallation.

The search for fruitful precatalyst / CTA couples remains in turn a difficult task, owing to the numerous factors governing a synergistic combination. A deeper understanding of the factors favouring propagation and transfer $v s$. $\beta \mathrm{H}$ abstraction may certainly help in this regard, ${ }^{2 ; 29 ; 52}$ as well as high throughput techniques. ${ }^{3}$ The different metal combinations reported for CCTP in the literature are summarized in Table 1. If numerous transition metals and rare earths have been assessed as catalysts, CTAs are essentially based on aluminium, magnesium and zinc. The quest for CTAs based on other metals may open the way to new findings. A fine tuning of the ligand environment around the transition metal is certainly the major factor allowing the reversible process at a rate that allows the transfer reaction to occur more rapidly than the propagation, and with a total transfer efficiency (CCG reactions). These latter conditions have been presently fulfilled essentially using dialkylmagnesium and zinc, but not yet with aluminium alkyls; this may be due to the fact that the chain transfer reaction between 
the transition metal and the aluminum alkyl is sterically more demanding for the three aluminium carbon bonds to grow concomitantly, especially at higher levels of oligomerization/polymerization. This requirement does not seem to be necessarily a prerequisite for industrial applications: this concept has already been claimed in early patents related to the synthesis of higher $\alpha$-olefins or alcohols using catalytic amounts of hafniumocene ${ }^{15}$ or actinidocene ${ }^{16}$ based catalysts to provide chain growth on aluminium alkyls in the presence of MAO, in which cases Schultz-Flory as well as Poisson distributions of the oligomeric chains were obtained, respectively.

The nature of the active species in CCTP, with numerous metals - pre-catalyst, co-catalyst, CTA in excess - involved, which is surrounded by uncertainties, should be discussed. Proposals have been made by several authors to clarify this point. ${ }^{1 f ; 2 ; 21 ; 26 ; 108-}$ ${ }^{109}$ The in situ formation of heterobimetallic complexes, $[\mathrm{TM}](\mu-\mathrm{R})_{2}[\mathrm{MGM}]$ (TM being a transition metal or a lanthanide and MGM a main group metal) depending on the cocatalyst is usually advanced (Scheme 33). The propagating species is in turn supposed to be a monometallic [TM]-R alkyl deriving from the dissociation of the afforementionned bimetallic complex (Scheme 33). In the presence of three metals, an equilibrium between bridged bimetallics like $[\mathrm{Fe}](\mu-\mathrm{R})_{2}[\mathrm{Zn}]$ and $[\mathrm{Fe}](\mu-\mathrm{R})_{2}[\mathrm{Al}]$ was advanced (Scheme 34). This may also be the case in Chain Shuttling Processes, where two metal catalysts interact each on their own side with the same metal-CTA.

Most of the efforts have been directed till now toward the quest for suitable catalysts/CTA combinations. Progress has certainly to be made in the conception of chain transfer agents. The design of chain transfer agents allowing a controlled or targeted transfer rate to the transition metal catalyst may, for instance, allow a better control over the length of the blocks in multiblock structures. The combination of the transalkylation function of the chain transfer agent with an ability to influence the 
selectivity of the reaction and/or the apparent co-monomer relative reactivity may be considered as a new paradigm for tuning (co-)polymer structures and even architectures via CCTP. This may take the form of a catalytic activity or an ability to play on the steric hindrance around the transition metal active species, among many others possibilities.

CCG reactions have been reported for various monomers, such as ethylene, styrene, and conjugated dienes. One of the challenges remaining is to find catalytic systems enabling perfect alkenes CCG, in which case the stereoselectivity has also to be addressed. If efficient isotactic and syndiotactic styrene CCTP have been reported, the 1,4-trans and 1,4-cis stereoselective CCTP of conjugated dienes occur with a modest transfer efficiency ( 2 to $15 \%$ and 10 to $26 \%$, respectively). On the other hand, the CCG reported for conjugated dienes occurs with a gradual increase of 3,4 enchainments at the detriment of 1,4 enchainments. An objective to fulfill is clearly to reach highly 1,4-cis and 1,4-trans stereoselective and 3,4 regioselective and eventually isotactic or syndiotactic CCG for conjugated diene polymerizations. Noteworthy is that CCG being a process by which all polymer chains are linked to $\mathrm{Al}, \mathrm{Mg}$ or $\mathrm{Zn}$, further chemistries are still going on and may be exploited for the synthesis of chain end functionalized polymers via direct functionalization or block copolymerizations with suitable comonomers for the synthesis of new diblock copolymers.

A promising feature of CCTP lies in CSP. This process involving two catalytic sites in a sequential way enables the facile one pot synthesis of multiblock microstructures and architectures. Interestingly, these copolymers are now produced on an industrial scale since 2006, available as INFUSE $^{\mathrm{TM}}$ olefinic block copolymers. ${ }^{12 \mathrm{~d}}$ The extension of chain shuttling copolymerization to other co-monomers combinations may afford the facile synthesis of a great variety of new thermoplastic elastomers. The 
one pot synthesis of stereoblock polymers exhibiting a multiblock architecture is also very attractive and needs to be extended to other monomers and stereoconfigurations. The transposition of the CSP concept to the ring-opening polymerization of cyclic esters by Cui and Chen represents a smart example of what can be done. ${ }^{110}$ 


\section{Acknowledgments}

Andreia Valente thanks the Portuguese Foundation for Science and Technology for her postdoctoral scholarship (SFRH/BPD/80459/2011).

\section{References}

1 (a) X. Olonde, A. Mortreux , F. Petit, J. Mol. Catal. 1993, 82, 75; (b) J.F. Pelletier, A. Mortreux, F. Petit, X. Olonde and K. Bujadoux in "Catalyst Design for Tailor made Polyolefins”, K. Soga and M. Terano Ed, Kodansha, Tokyo, 1994, pp. 249; (c) J. F. Pelletier, K. Bujadoux, X. Olonde, E. Adisson, A. Mortreux , T. Chenal, Fr 9504203, April 5, 1995, US Patent 5,779,942; (d) J. F. Pelletier, A. Mortreux, X. Olonde, K. Bujadoux, Angew. Chem. 1996, 35, 1854; (e) K. Bujadoux, T. Chenal, C. Fouga, X. Olonde, J. F. Pelletier, A.Mortreux in : «Metalorganic Catalysts for Synthesis and Polymerization », W. Kaminsky, Ed., Springer, Berlin 1999, pp. 590; (f) T. Chenal, X. Olonde, J. F. Pelletier, K. Bujadoux, A. Mortreux, Polymer 2007, 48, 1844.

2 G. J. P. Britovsek, S. A. Cohen, V.C. Gibson, M. van Meurs, J. Am. Chem. Soc. 2004, 126, 10701.

3 D. J. Arriola, E. M. Carnahan, P. D. Hustad, R. L. Kuhlman, T. T. Wenzel, Science 2006, 312,714 .

4 P. Zinck, A. Valente, A. Mortreux, M. Visseaux, Polymer 2007, 48, 4609.

5 R. Kempe, Chem. Eur. J. 2007, 13, 2764.

6 S. B. Amin, T. J. Marks, Angew. Chem. 2008, 47, 2006.

7 L. R. Sita, Angew. Chem. Int. Ed. 2009, 48, 2464.

8 B. Heurtefeu, F. Vaultier, R. Leino, C. Boisson, H. Cramail, Single Site Catalysts in Encyclopedia of Polymer Science and Technology - Wiley 4th edition, 2012, 136.

9 K. Ziegler et al., Angew. Chem. 1952, 64, 323. 
10 The chain transfer efficiency is defined as the ratio of the alkyl groups of the chain transfer agent involved in the chain transfer, i.e leading to the growth of a macromolecular chain.

11 F. D’Agosto, C. Boisson, Aust. J. Chem 2010, 63, 1155.

12 (a) V.C. Gibson, V.C. Science 2006, 312, 703; (b) Busico, V. Macromol. Chem. Phys. 2007, 208, 26; (c) Zintl, M.; Rieger B. Angew. Chem. Int. Ed. 2007, 46, 333; (d) Hustad, P.D. Science 2009, 325, 704; (e) Zinck, P. Polym. Int. 2012, 61, 2. 13 (a) S.B Amin, T.J. Marks, Angew. Chem. 2008, 47, 2; (b) T.C. Chung, Prog. Polym. Sci. 2002, 27, 39; (c) J.Y. Dong, Y. Hu, Coor. Chem. Rev. 2006, 250, 47; (d) R.C. Lopez, F. D’Agosto, C. Boisson, Prog. Polym. Sci. 2007, 32, 419; (e) J. Mazzolini, E. Espinosa, F. D'Agosto, C. Boisson, Polym. Chem. 2010, 1, 793.

14 The use of CCTP and chain shuttling to make olefin block copolymers has also been discussed in (a) P.D. Hustad, R.L. Kuhlman, C. Li Pi Shan, Chain Shuttling Catalysis and Olefin Block Copolymers. In: Matyjaszewski K and Möller M (eds.) Polymer Science: A Comprehensive Reference, Vol 3, Amsterdam, Elsevier, 2012, 699; (b) T.T. Wenzel, D.J. Arriola, E.M. Carnahan, P.D. Hustad, R.L. Kuhlman, Metal Catalysts in Olefin Polymerization. Topics in Organometallic Chemistry, Vol. 26, Guan, Z, Springer-Verlag: Berlin, 2009, 65.

15 Samsel, E.G. (Ethyl Corporation), EP 0539876, 1993

16 Samsel, E. G.; Eisenberg, D. C., (Ethyl Corporation), EP 0574854, 1993.

17 J. S. Rogers, G. C. Bazan, Chem. Commun. 2000, 1209.

18 G. C. Bazan, J. S. Rogers, C. C. Fang, Organometallics 2001, 20, 2059.

19 G. Mani, F. P. Gabbai, Angew. Chem. 2004, 116, 2313.

20 G. Mani, F : P. Gabbai, J. Organomet. Chem 2005, 690, 5145. 
21 W. P. Kretschmer, A. Meetsma, B. Hessen, T. Schmalz, S. Qayyum, R. Kempe, Chem. Eur. J. 2006, 12, 8969.

22 P.D. Hustad, R.L. Kuhlman, E.M. Carnahan, T.T. Wenzel, D.J. Arriola, Macromolecules 2008, 41, 4081

23 R.L. Kuhlman, T.T. Wenzel, Macromolecules 2008, 41, 4090

24 W. P. Kretschmer, T. Bauer, B. Hessen, R. Kempe, Dalton Trans. 2010, 39, 6847.

25 I. Haas, W. P. Kretschmer, R. Kempe, Organometallics 2011, 30, 4854.

26 C. Boisson, V. Monteil, D. Ribour, R. Spitz, F. Barbotin, Macromol. Chem. Phys. 2003, 204, 5145 .

27 F. Rouholahnejad, D. Mathis, P. Chen, Organometallics 2010, 29, 294.

28 G. J. P. Britovsek, S. A. Cohen, V. C. Gibson, P. J. Maddox, M. van Meurs, Angew. Chem. Int. Ed. 2002, 41, 489.

29 M. van Meurs, G. J. P. Britovsek, V. C. Gibson, S. A. Cohen, J. Am. Chem. Soc. 2005, 127, 9913.

30 W. Zhang, J. Wei, L. R. Sita, Macromolecules 2008, 41, 7829.

31 P. D. Hustad, R. L. Kuhlman, D. J. Arriola, E. M. Carnahan, T. T. Wenzel, Macromolecules 2007, 40, 20, 7061.

32 S. Lieber, H.-H. Brintzinger, Macromolecules 2000, 33, 9192.

33 S. Hild, C. Cobzaru, C. Troll, B. Rieger, Macromol. Chem. Phys. 2006, 207, 665.

34 E. Barsties, S. Schaible, M.-H. Prosenc, U. Rief, W. Röll, O. Weyand, B. Dorer, H. H. Brintzinger, J. Organomet. Chem. 1996, 520, 63.

35 G. Fan, J.-Y. Dong, J. Mol. Cat. A: Chemical 2005, 236, 246.

36 N. Naga, K. Mizunuma, Polymer 1998, 39, 21, 5059.

37 R. Leino, H. J. G. Luttikhedde, P. Lehmus, C.-E. Wilén, R. Sjöholm, A. Lehtonen, J. V. Seppälä, J. H. Näsman, Macromolecules 1997, 30, 3477. 
38 L. Resconi, F. Piemontesi, I. Cammurati, D. Balboni, Organometallics 1996, 15, 5046.

39 A. Tynys, J. L. Eilertsen, E. Rytter, Macromol. Chem. Phys. 2006, 207, 295.

40 W. Zhang, L. R. Sita, J. Am. Chem. Soc. 2008, 130, 442.

41 T. Shiono, S. Yoshida, H. Hagihara, T. Ikeda, Applied Catalysis A: Chemical 2000, $200,145$.

42 J. Kukral, P. Lehums, M. Klinga, M. Leskelä, B. Rieger, Eur. J. Inorg. Chem. 2002, 1349.

43 V. Busico, R. Cipullo, J.C. Chadwick, J.F. Modder, O. Sudmeijer, Macromolecules 1994, 27, 7538 .

44 J. Wei, W. Zhang, L. R. Sita, Angew. Chem. Int. Ed. 2010, 49, 1768.

45 S. Bogaert, T. Chenal, A. Mortreux, G. Nowogrocki, C. W. Lehmann, J.-F. Carpentier, Organometallics 2001, 20, 199.

46 S. Bogaert, J. F. Carpentier, T. Chenal, A. Mortreux, G. Ricart, Macromol. Chem. Phys. 2000, 201, 1813.

47 Y. Sarazin, T. Chenal, A. Mortreux, H. Vezin, J. F. Carpentier, J. Mol. Catal. 2005, $238,207$.

48 P. Zinck, M. Visseaux, A. Mortreux, Z. Anrg. Allg. Chem. 2006, 632, 1943.

49 A. Rodrigues, E. Kirillov, B. Vuillemin, A. Razavi, J. F. Carpentier, J. Mol. Catal. A 2007, 273, 87 .

50 L. Annunziata, A.-S. Rodrigues, E. Kirillov, Y. Sarazin, J. Okuda, L. Perrin, L. Maron, J.-F. Carpentier, Macromolecules 2011, 44, 3312.

51 Y. Sarazin, P. de Frémont, L. Annunziata, M. Duc, J.-F. Carpentier, Adv. Synth. Catal. 2011, 353, 1367. 
52 P. Zinck, A. Valente, F. Bonnet, A. Violante, A. Mortreux, M. Visseaux, S. Ilinca, R. Duchateau, P. Roussel, J. Polym. Sci.: Part A : Polym. Chem. 2010, 48, 802.

53 R. Po, N. Cardi, L. Abis, Polymer 1998, 39, 4, 959.

54 T. H. Newman, K. K. Borodychuk (Dow Chemical Co. USA). Patent US 5, 428, $120,1995$.

55 L. Friebe, O. Nuyken, W. Obrecht, Adv. Polym. Sci. 2006, 204, 1.

56 L. Friebe, O. Nuyken, H. Windish, W. Obrecht, Macromol. Chem. Phys. 2002, 203, 1055.

57 G. S. S. Rao, V. K. Upadhyay, R. C. Jain, Journal of Applied Polymer Science 1999, $71,595$.

58 L. Friebe, H. Windish, O. Nuyken, W. Obrecht, J. Macromol. Sci. 2004, A41, 3, 245.

59 L. Friebe, J. M. Müeller, O. Nuyken, W. Obrecht, J. Macromol. Sci. 2006, 204, 1.

60 L. Friebe, J. M. Müller, O. Nuyken, W. Obrecht, J. Macromol. Sci. 2006, 43, 11.

61 J. B. Nickaf, R. P. Burford, R. P. Chaplin, J. Polym. Sci., Polym. Chem. 1995, 33, 1125 .

62 C. Fan, C. Bai, H. Cai, Q. Dai, X. Zhang, F. Wang, J. of Polym. Sci: Part A: Polym. Chem. 2010, 48, 4768.

63 S. Kaita, M. Yamanaka, A.C. Horiuchi, Y. Wakatsuki, Macromolecules 2006, 39, 1359.

64 Y. Taniguchi, W. Dong, T. Katsumata, M. Shiotsuki, T. Masuda, Polymer Bulletin 2005, 54, 173.

65 M.J. Vitorino, P. Zinck, M. Visseaux, Eur. Polym. J. 2012, 48, 1289.

66 F. Wang, C. Zhang, Y. Hu, X. Jia, C. Bai, X. Zhang, Polymer 2012, 53, 6027.

67 M.F.K. Takahashi, M. De Lima, W.L. Polito, Polymer Bull. 1997, 38, 455.

68 P. Zinck, M. Terrier, A. Mortreux, M. Visseaux, Polym. Test. 2009, 28, 106 
69 A. Valente, P. Zinck, M. J. Vitorino, A. Mortreux, M. Visseaux, J. Polym. Sci.: Part A: Polym. Chem. 2010, 48, 4640.

70 M. Visseaux, M. Mainil, M. Terrier, A. Mortreux, P. Roussel, T. Mathivet, M. Destarac, Dalton Trans. 2008, 4558.

71 Z. Jian, D. Cui, Z. Hou, X. Li, Chem. Commun. 2010, 46, 3022.

72 J. Gromada, L. le Pichon, A. Mortreux, F. Leising, J.F. Carpentier, J. Organomet. Chem. 2003, 683, 44.

73 A. Valente, P. Zinck, A. Mortreux, M. Visseaux, Macromol. Rapid Commun. 2009, 30,528 .

74 H.Yasuda, Y. Nakano, K.Natsukawa, H. Tani, Macromolecules 1978, 11, 586.

75 S. Loughmari, A. Hafid, A. Bouazza, A. El Bouadili, P. Zinck, M. Visseaux, J. Polym. Sci., Polym. Chem 2012, 50, 2989.

76 S. Li, W. Miao, T. Tang, W. Dong, X. Zhang, D. Cui, Organometallics 2008, 27, 718.

77 L. Annunziata, M. Duc, J.F. Carpentier, Macromolecules 2011, 44, 7158.

78 D.-J. Byun, D.-K. Shin, S. Y. Kim, Macromol. Rapid Commun. 1999, 20, 419.

79 D.-J. Byun, S. Y. Kim, Macromolecules 2000, 33, 1921.

80 T. Yoshida, N. Koga, K. Morokuma, Organometallics 1995, 14, 746.

81 T. K. Woo, L. Fan, T. Ziegler, Organometallics 1994, 13, 2252.

82 B. J. Burger, M. E. Thompson, W. D. Cotter, J. E. Bercaw, J. Am. Chem. Soc. 1990, $112,1566$.

83 K. Thorshaug, E. Rytter, M. Ystenes, Macromol. Rapid Commun. 1997, 18, 715.

84 K. Hakala, T. Helaja, B. Löfgren, Polymer Bulletin 2001, 46, 123.

85 A. Tynys, T. Saarinen, K. Hakala, T. Helaja, T. Vanne, P. Lehmus, B. Löfgren, Macromol. Chem. Phys. 2005, 206, 1043. 
86 N. N. Bhrian, H.-H. Brintzinger, D. Ruchatz, G. Fink, Macromolecules 2005, 38, 2056.

87 (a) E. G. Hoffmann, Trans. Faraday Soc. 1962, 58 642; (b) O. Yamamoto, K. Hayamizu, J. Phys. Chem. 1968, 72, 822.

88 A. Valente, P. Zinck, A. Mortreux, M. Visseaux, J. Polym. Sic. Part A : Polym. Chem. 2011, 49, 1615.

89 A. Valente, P. Zinck, A. Mortreux, M. Bria, M. Visseaux, J. Polym. Sci Part A : Polym. Chem. 2011, 49, 3778.

90 B. Wang, D. Cui, K. Lv, Macromolecules 2008, 41, 1983.

91 L. Zhang, Y. Luo, Z. Lou, J. Am. Chem. Soc. 2005, 127, 14562.

92 S. Li, D. Cui, D. Li, Z. Hou, Organometallics 2009, 28, 4814.

93 C. Döring, W. P. Kretschmer, R. Kempe, Eur. J. Inorg. Chem. 2010, 18, 2853.

94 M. Visseaux, F. Bonnet, Coord. Chem. Rev. 2011, 255, 357.

95 J.- S. Um, J.-Y. Liu, S.R. Liu, Y.-S. Li, Polymer 2009, 50, 5059.

96 A. Xiao, L. Wang, Q. Liu, H. Yu, J. Wang, J. Huo, Q. Tan, J. Ding, W. Ding, A. M. Amin, Macromolecules 2009, 42, 1834.

97 In a chain walking polymerization, the active growing site isomerizes to an internal position on the polymer backbone during propagation, so that the next monomer unit can be assembled onto the polymer backbone instead of at the end. See Z. Guan, P. M. Cotts, E. F. McCord, S. J. McLain, Science 1999, 283, 2059.

98 F. Alfano, H. W. Boone, V. Busico, R. Cipullo, J. C. Stevens, Macromolecules 2007, 40, 7736 .

99 A. Tynys, J. L. Eilertsen, J. V. Seppala, E. Rytter, J. Polym. Sci., Polym. Chem. 2007, 45, 1364. 
100 H. P. Wang, D. U. Khariwala, W. Cheung, S. P. Chum, A. Hiltner, E. Baer, Macromolecules 2007, 40, 2852.

101 D. U. Khariwala, A. Taha, S. P. Chum, A. Hiltner, E. Baer, Polymer 2008, 49, 1365.

102 R.L. Kuhlman, J. Klosin, Macromolecules 2010, 43, 7903.

103 J. Wei, W. Zhang, R. Wickham, L. R. Sita, Angew. Chem. Int. Ed. 2010, 49, 9140.

104 I. Bruaseth, E. Rytter, Macromolecules 2003, 36, 3026.

105 L. Pan, K. Zhang, M. Nishiura, Z. Hou, Angew. Chem. 2011, 50, 12012.

106 H. Zhang, Y. Luo, Z. Hou, Macromolecules 2008, 41, 1064.

107 M. Zhang, T.W. Karjala, P. Jain, Ing. Eng. Chem. Res. 2010, 49, 8135.

108 (a) M. Bochmann, S.J. Lancaster, J. Organomet. Chem. 1995, 497, 55; (b) M.

Bochmann, S. J. Lancaster, Angew. Chem., 1994, 33, 1634.

109 J.M. Camara, R.A. Petros, J.R.Norton, J. Am. Chem. Soc. 2011, 133, 5263.

110 W. Zhao, Y. Wang, X. Liu, X. Chen, E.Y.X Chen, Chem. Com., 2012, 48, 6375. 


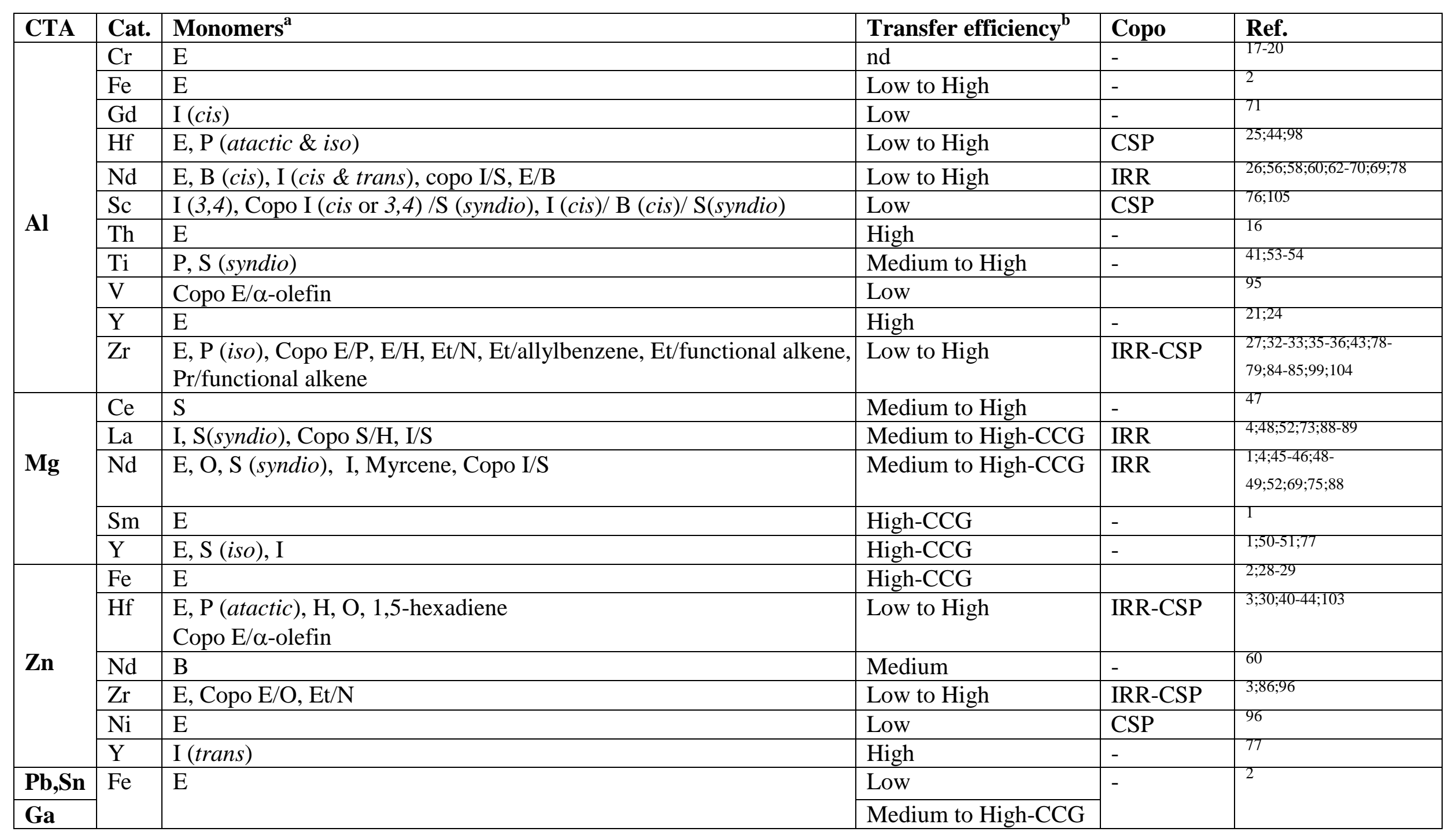


Table 1. Metal combinations used for CCTP. ${ }^{a} \mathrm{E}=$ =thylene, $\mathrm{P}=$ propylene, $\mathrm{H}=1$-hexene, $\mathrm{O}=1$-octene, $\mathrm{S}=$ styrene, $\mathrm{B}=\mathrm{butadiene}, \mathrm{I}=\mathrm{isoprene}$, N=norbornene; ${ }^{b}$ Transfer efficiency rating : low $0-33 \%$, medium 33-66\%, high $>66 \%$, CCG $100 \%$ or close to; ${ }^{c}$ when copolymerization is concerned, $\mathrm{CSP}=$ chain shuttling polymerization; $\mathrm{IRR}=$ =increase in comonomer reactivity ratio 


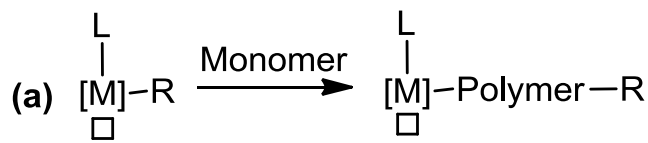

(b)<smiles>I[AlH][I-]</smiles>

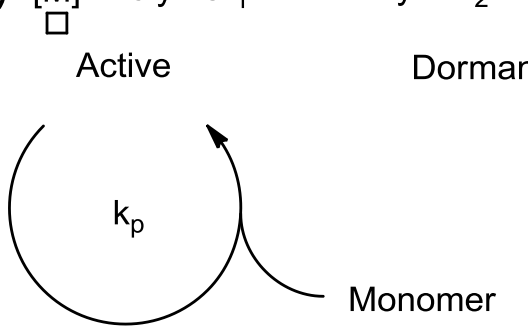

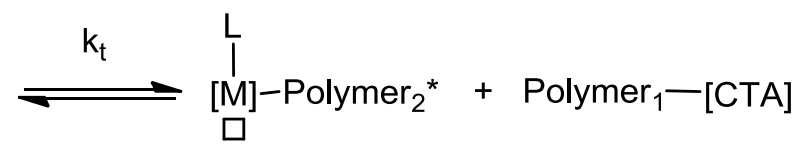

Active

Dormant

Scheme 1. Classical coordinative polymerization (a) vs. Coordinative Chain

Transfer Polymerization (b) 


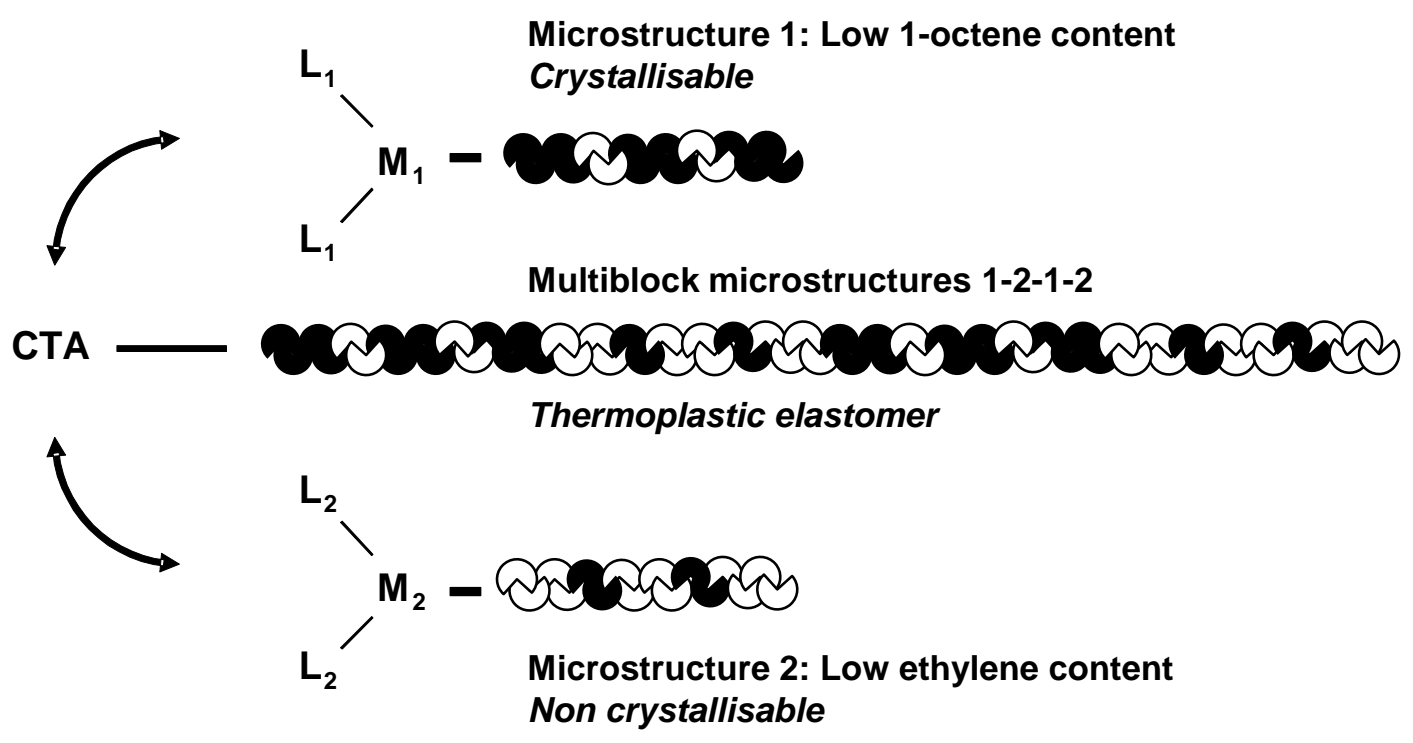

Scheme 2. Chain shuttling copolymerization. ${ }^{3} M_{i}$ represents transition metals allowing propagation, $L_{i}$ ligands, and CTA the chain transfer or chain shuttling agent.

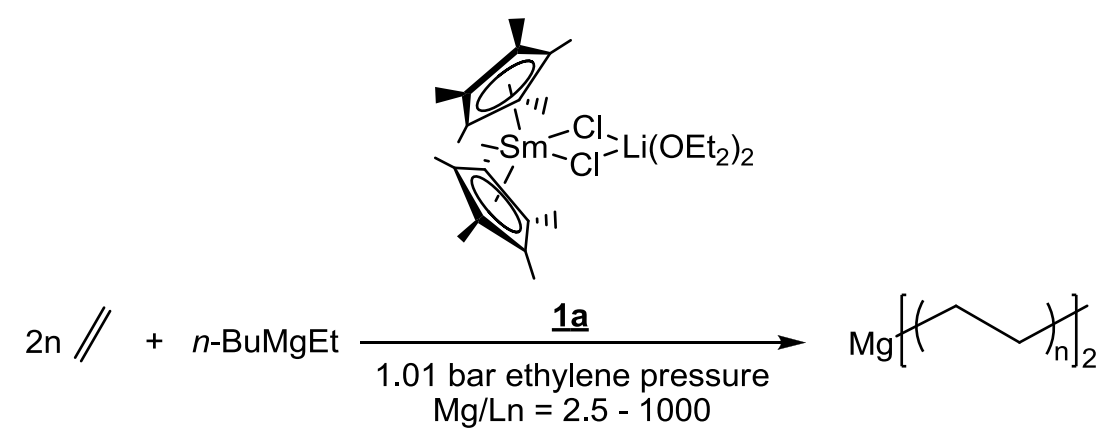

Scheme 3. Lanthanide catalyzed polyethylene chain growth on magnesium $(\mathrm{CCG})^{1}$; reaction conducted at $80{ }^{\circ} \mathrm{C}$ producing up to $2000 \mathrm{~g} / \mathrm{mol}$ polyethylene. 


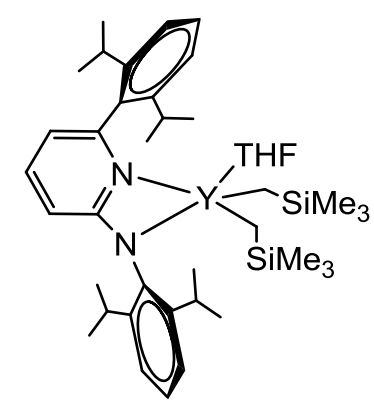
$\mathrm{n} / /+\mathrm{Al}(i-\mathrm{Bu})_{3} \frac{\underline{\mathbf{2}}}{\left[\mathrm{R}_{2} \mathrm{~N}\left(\mathrm{CH}_{3}\right) \mathrm{H}\right]^{+}\left[\mathrm{B}\left(\mathrm{C}_{6} \mathrm{~F}_{5}\right)_{4}\right]^{-}}$
$\left(\mathrm{R}=\mathrm{C}_{16} \mathrm{H}_{31}-\mathrm{C}_{18} \mathrm{H}_{35}\right)$
5 bar ethylene pressure
$\mathrm{Al} / \mathrm{Y}=0-100$

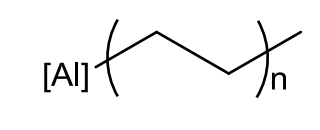

Scheme 4. Ethylene CCTP using organoyttrium cation derived from $\underline{2}$ and $\mathrm{Al}^{i} \mathrm{Bu}_{3}{ }^{21}$; reaction conducted at $80^{\circ} \mathrm{C}$ producing up to $4000 \mathrm{~g} / \mathrm{mol}$ polyethylene.

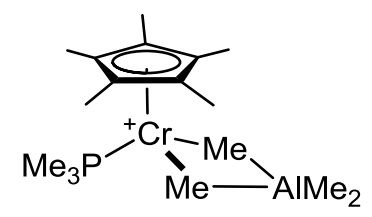

Scheme 5. Bridging species that could be formed during the polymerization of ethylene using $\underline{4}$ and MAO $^{17,18}$

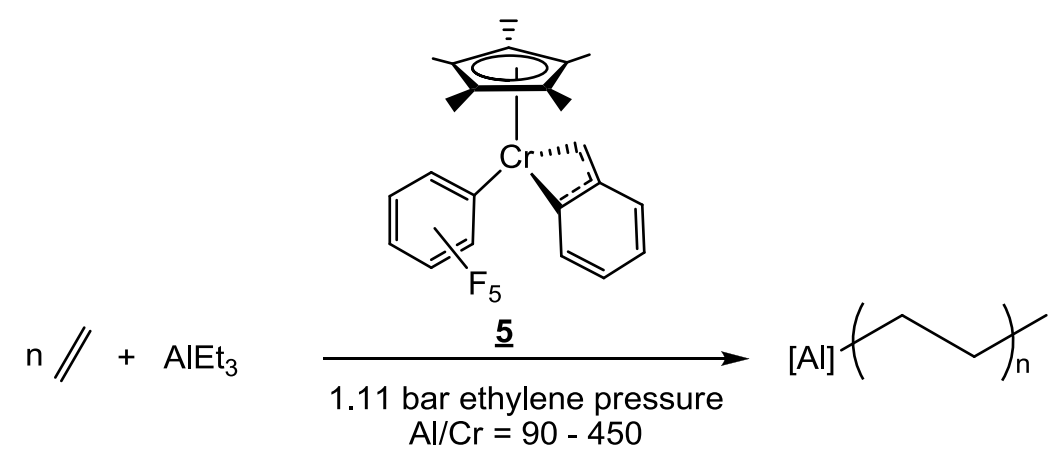

Scheme 6. Ethylene CCTP using catalyst $\underline{5}$ and $\mathrm{AlEt}_{3}{ }^{19}$; reaction conducted at 25

${ }^{\circ} \mathrm{C}$ producing up to $500 \mathrm{~g} / \mathrm{mol}$ polyethylene. 


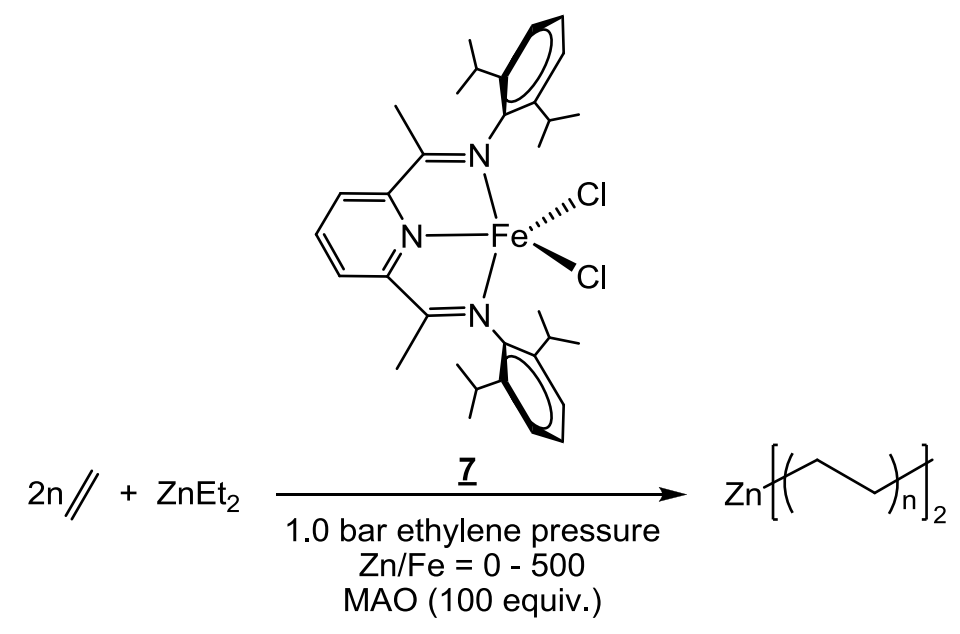

Scheme 7. Iron catalyzed polyethylene chain growth on zinc $(\mathrm{CCG})^{\mathbf{2 , 2 8}}$; reaction conducted at room temperature producing up to $3000 \mathrm{~g} / \mathrm{mol}$ polyethylene.

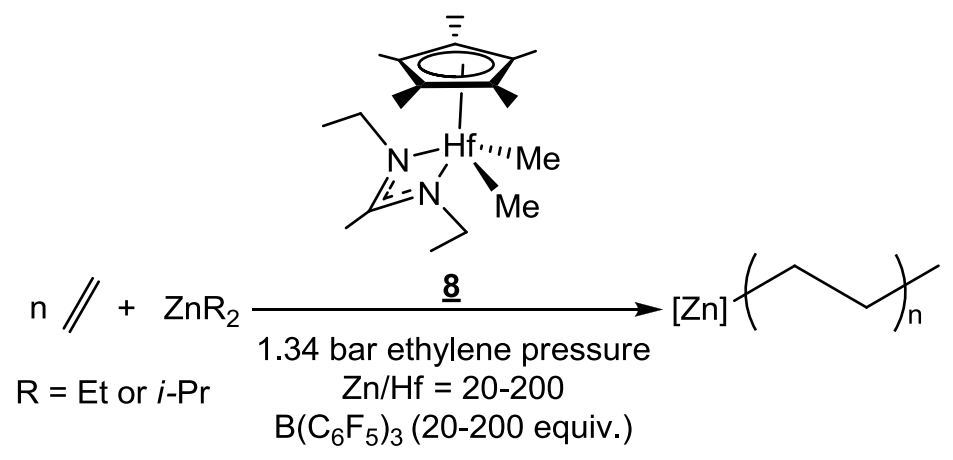

Scheme 8. Ethylene CCTP between the catalyst $\underline{8}$ and $\mathrm{ZnR}_{2}{ }^{30}$; reaction conducted at $25^{\circ} \mathrm{C}$ producing up to $670 \mathrm{~g} / \mathrm{mol}$ polyethylene. 


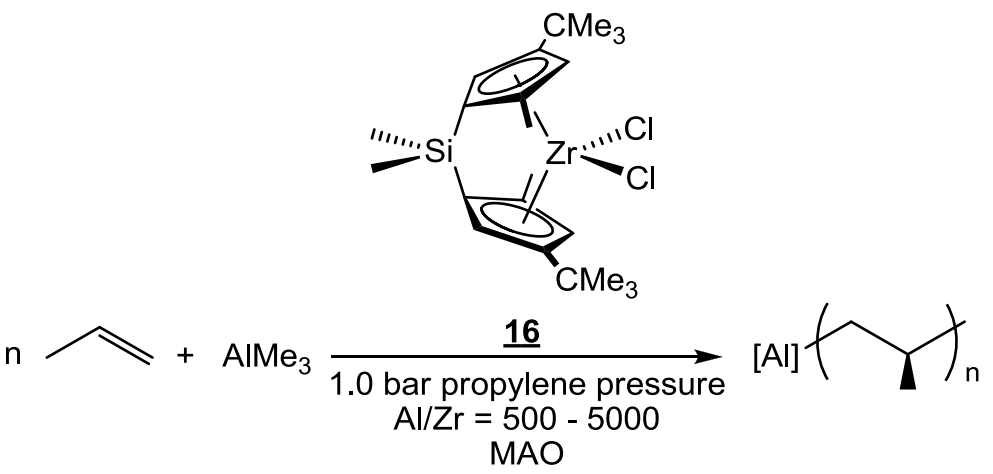

Scheme 9. Propylene CCTP using catalyst $\underline{16}$ and $\mathrm{AlMe}_{3} ;{ }^{32}$ reaction conducted at $40{ }^{\circ} \mathrm{C}$ producing up to $2100 \mathrm{~g} / \mathrm{mol} 95-99 \%$ [ $\mathrm{mmmm}$ ] polypropylene.

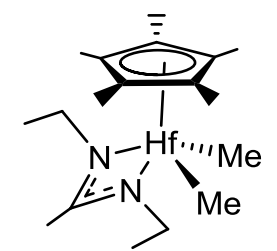

$\mathrm{n} \longrightarrow+\mathrm{ZnEt}_{2}$

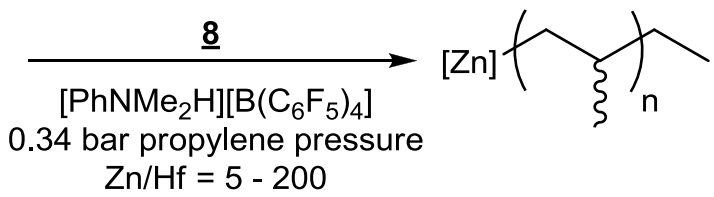

Scheme 10. Propylene CCTP using $\underline{8}$ and $\mathrm{ZnEt}_{2} ;{ }^{30,40}$ reaction conducted at $0{ }^{\circ} \mathrm{C}$ producing up to $33300 \mathrm{~g} / \mathrm{mol}$ atactic polypropylene with $\mathrm{PDI} \leq 1.1$. 


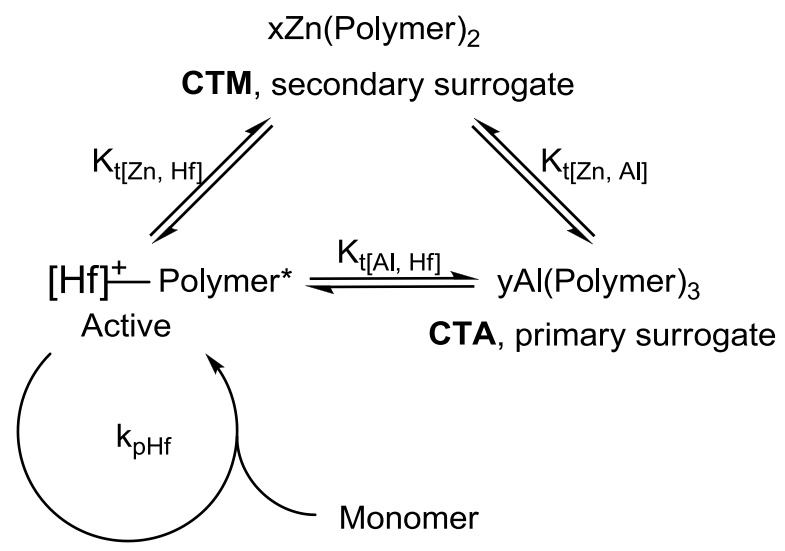

Scheme 11. Propylene ternary CCTP using $\underline{8}$ as the active chain-growth initiator, $\operatorname{AlR}_{3}\left(R=\right.$ ethyl, $n$-propyl, isobutyl) as the chain transfer agent (CTA) and $\mathbf{Z n E t}_{2}$ as chain transfer mediator $(\mathrm{CTM}) .{ }^{44}$ Polymer* represents a growing polymeric chain. $K_{\mathrm{pHf}}$ and $K_{t}$ are the rate constants for propagation on the hafnium and reversible transfer, respectively.

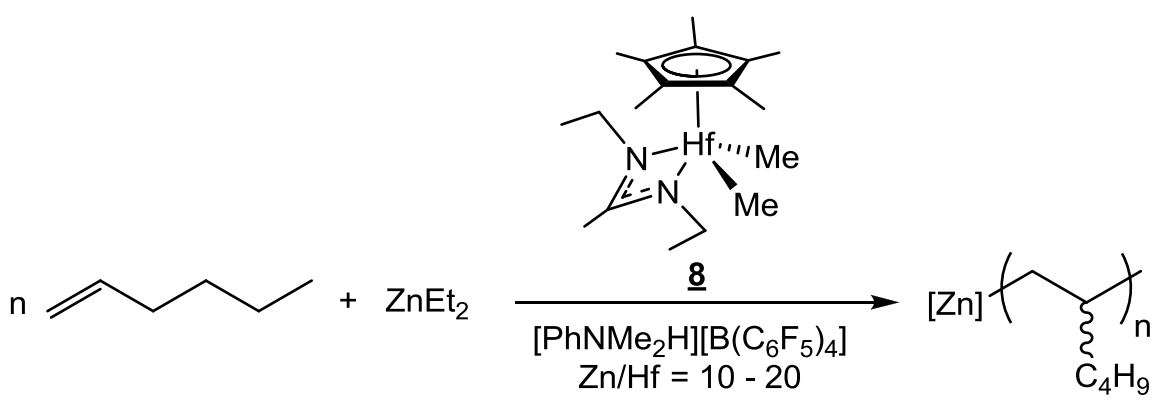

Scheme 12. Hexene CCTP using Hf based complex $\underline{8}$ and $\mathrm{ZnEt}_{2} ;{ }^{30}$ reaction conducted at $-10{ }^{\circ} \mathrm{C}$ producing up to $6650 \mathrm{~g} / \mathrm{mol}$ atactic polyhexene. 


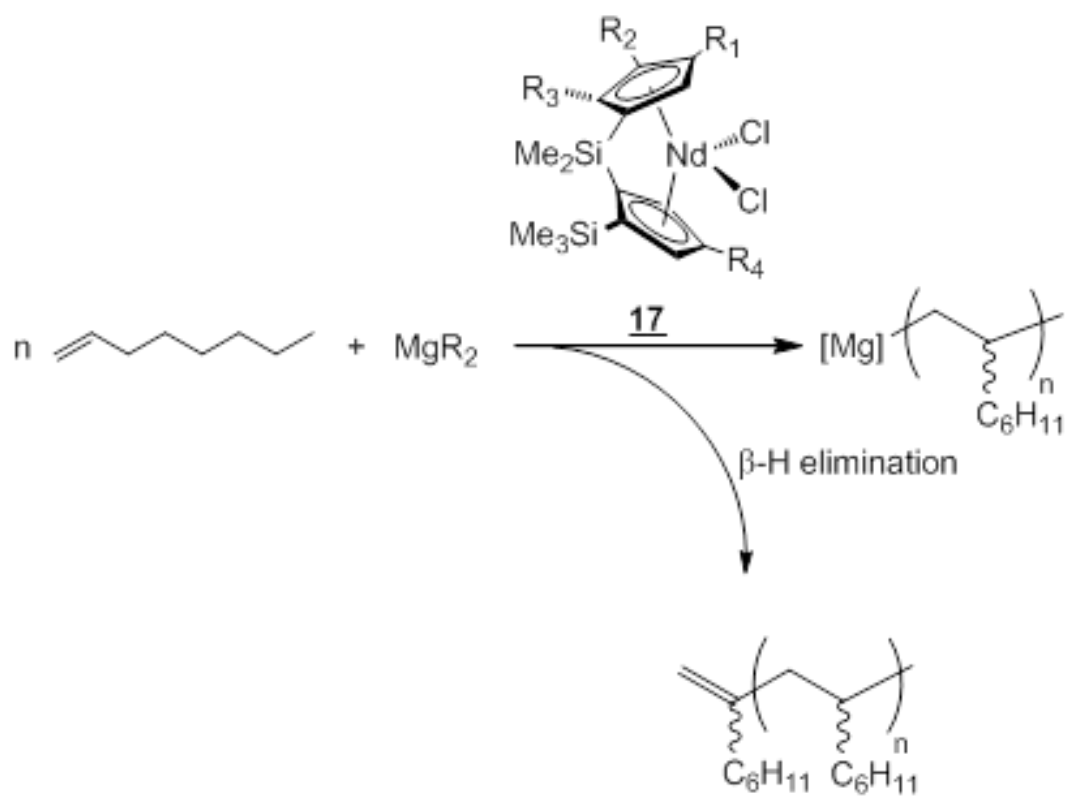

Scheme 13. Octene polymerization using neodymocenes and dialkylmagnesium showing the simultaneous occurrence of $\beta$-H elimination. ${ }^{45}$

\section{Chain transfer polymerization}

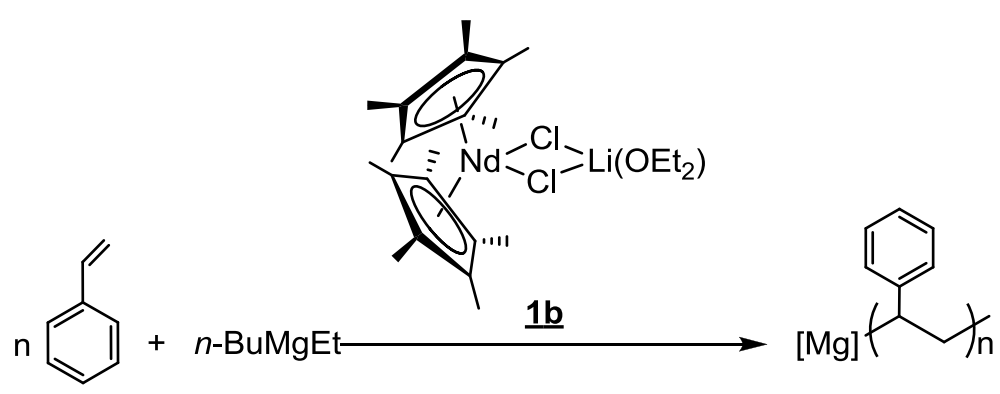

Radical Polymerization

$$
\begin{aligned}
& \mathrm{R}-\mathrm{Mg}-\mathrm{R}^{\prime}+\mathrm{P}-(\mathrm{S})_{\mathrm{m}}^{\bullet} \rightleftharpoons \mathrm{P}-(\mathrm{S})_{\mathrm{m}}-\mathrm{Mg}-\mathrm{R}^{\prime}+\mathrm{R}^{\circ} \\
& \mathrm{P}-(\mathrm{S})_{\mathrm{m}}-\mathrm{Mg}-\mathrm{R}^{\prime}+\mathrm{P}-(\mathrm{S})_{\mathrm{n}}^{\circ} \longrightarrow \mathrm{P}-(\mathrm{S})_{\mathrm{m}}-\mathrm{Mg}-(\mathrm{S})_{\mathrm{n}}-\mathrm{P}+\mathrm{R}^{\bullet} \\
& \mathrm{R}^{\circ}+\mathrm{mS} \longrightarrow \mathrm{R}-(\mathrm{S})_{\mathrm{m}}^{\cdot}
\end{aligned}
$$

Scheme 14. Polymerization of styrene by chlorolanthanidocene/dialkyl magnesium system $^{46}$; $S$ = styrene monomer and R, R' = Bu and Et. 


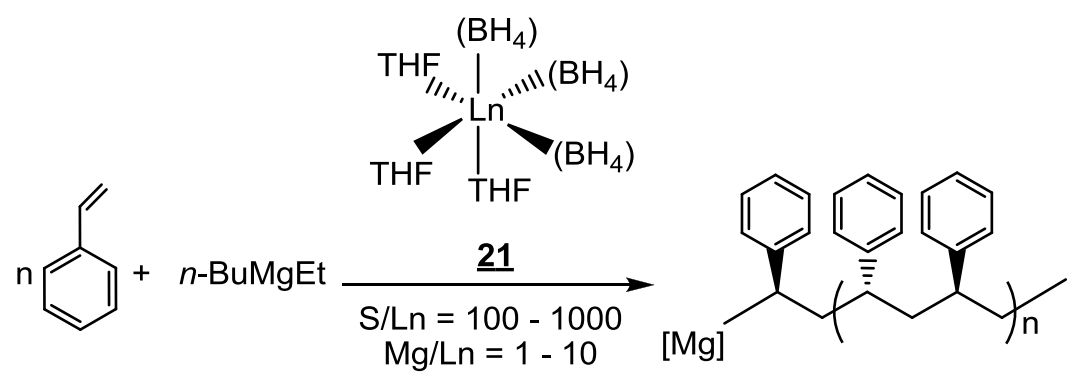

Scheme 15. Styrene polymerization using $\operatorname{Ln}\left(\mathrm{BH}_{4}\right)_{3}(\mathrm{THF})_{3}$ and $n$ BuMgEt; ${ }^{48}$ reaction conducted at $50{ }^{\circ} \mathrm{C}$ producing up to $19200 \mathrm{~g} / \mathrm{mol}$ atactic polystyrene with $81 \%$ chain transfer efficiency; $\mathrm{S}=$ styrene monomer.

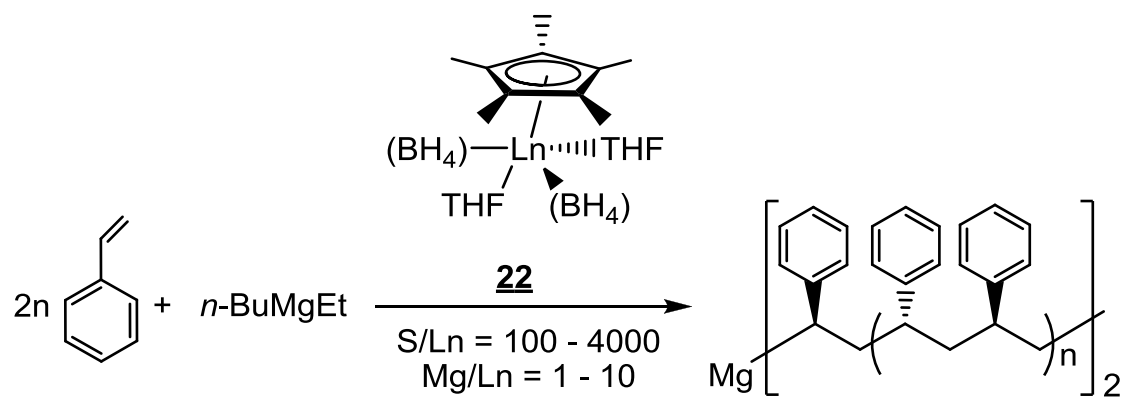

Scheme 16. Half-lanthanidocene catalyzed polystyrene chain growth polymerization on magnesium $(\mathrm{CCG}) ;^{4,52}$ reaction conducted at $50{ }^{\circ} \mathrm{C}$ producing up to $16000 \mathrm{~g} / \mathrm{mol} 85 \%$ syndiotactic polystyrene with $\approx 100 \%$ chain transfer efficiency; $R=$ Bu or Et and $S=$ styrene monomer. 

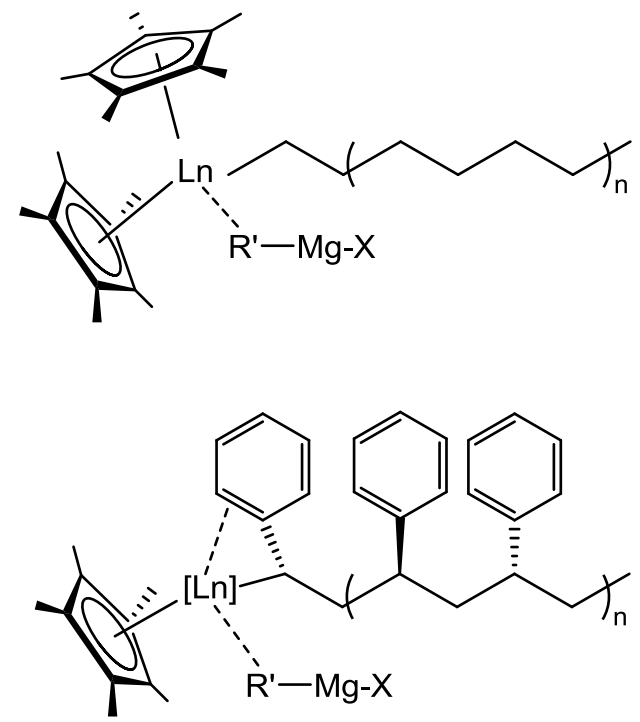

Scheme 17. Analogy between lanthanidocene mediated polyethylene CCG and half-lanthanidocene mediated polystyrene CCG.

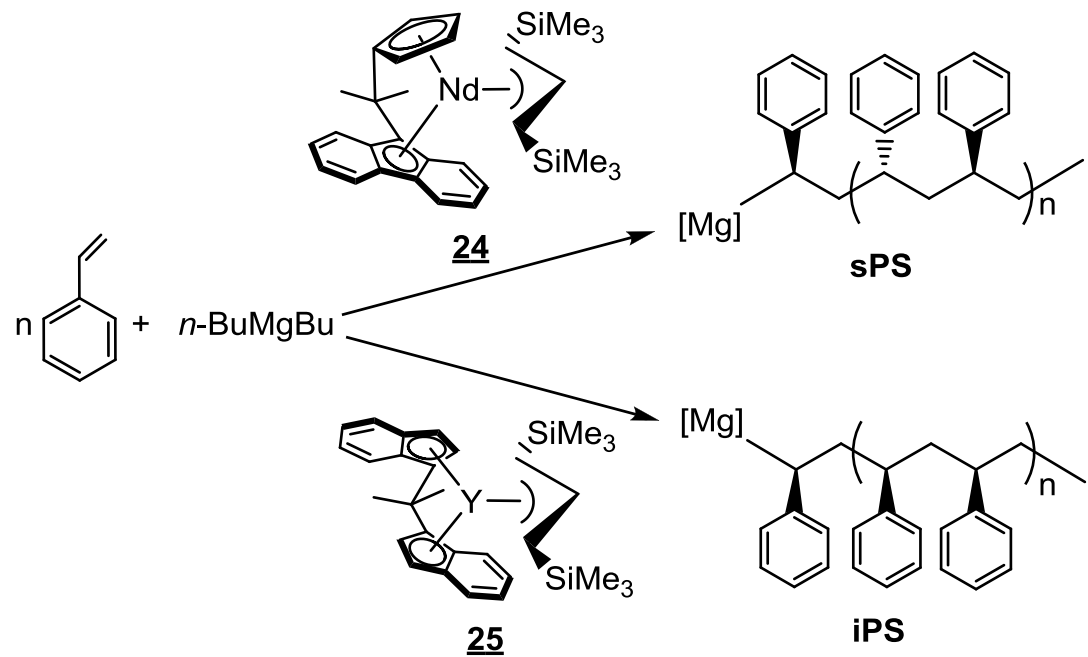

Scheme 18. Styrene polymerization using the allyl ansa-lanthanidocenes $\underline{24}$ and $\underline{25}$ and $n \mathrm{BuMgBu} ;{ }^{51}$ reaction conducted at $80-100{ }^{\circ} \mathrm{C}$ producing syndiotactic or isotactic polystyrenes, respectively. 


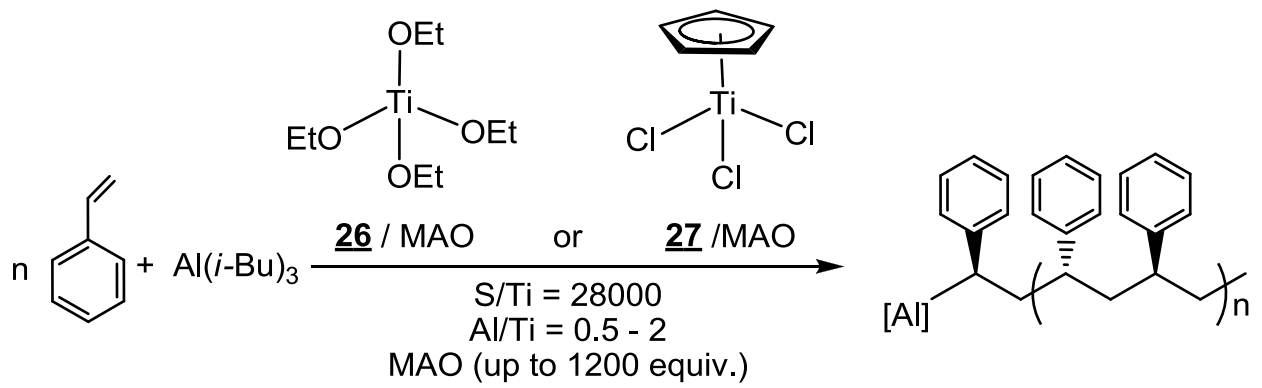

Scheme 19. Syndiotactic polystyrene CCTP using titanium complexes and $\mathrm{AliBu}_{3} ;^{53}$ reaction conducted at $60^{\circ} \mathrm{C}$ producing up to $400000 \mathrm{~g} / \mathrm{mol}$ highly syndiotactic polystyrene; $S$ = styrene monomer.

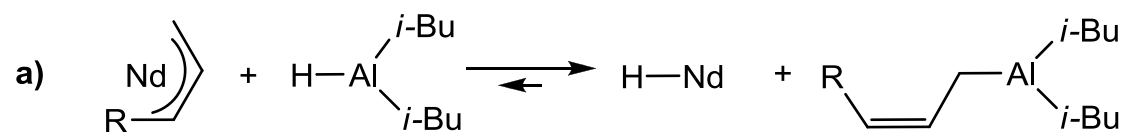

b) $\mathrm{Nd})\rangle+i-\mathrm{Bu}-\left.\mathrm{Al}\right|_{i-\mathrm{Bu}} ^{i-\mathrm{Bu}} \rightleftarrows i-\mathrm{Bu}-\mathrm{Nd}+\mathrm{R} \rightleftharpoons \overbrace{}^{\mathrm{A} I^{i-\mathrm{Bu}}}$

Scheme 20. Transfer reactions with a) $\mathrm{AlH}^{i} \mathrm{Bu}_{2}$; b) $\mathrm{Al}^{i} \mathrm{Bu}_{3}{ }^{58}$ 


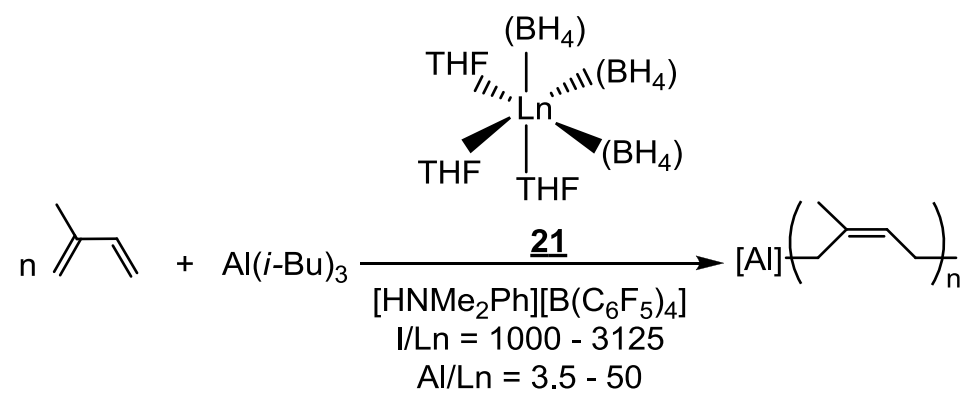

Scheme 21. Cationic 1,4-cis isoprene polymerization using $\underline{21}$ in combination with $\mathrm{Al}^{i} \mathrm{Bu}_{3} ;{ }^{70}$ reaction conducted at $20-50{ }^{\circ} \mathrm{C}$ producing up to $120000 \mathrm{~g} / \mathrm{mol}$ of high cispolyisoprene with 4-6\% chain transfer efficiency; $I$ = isoprene monomer.

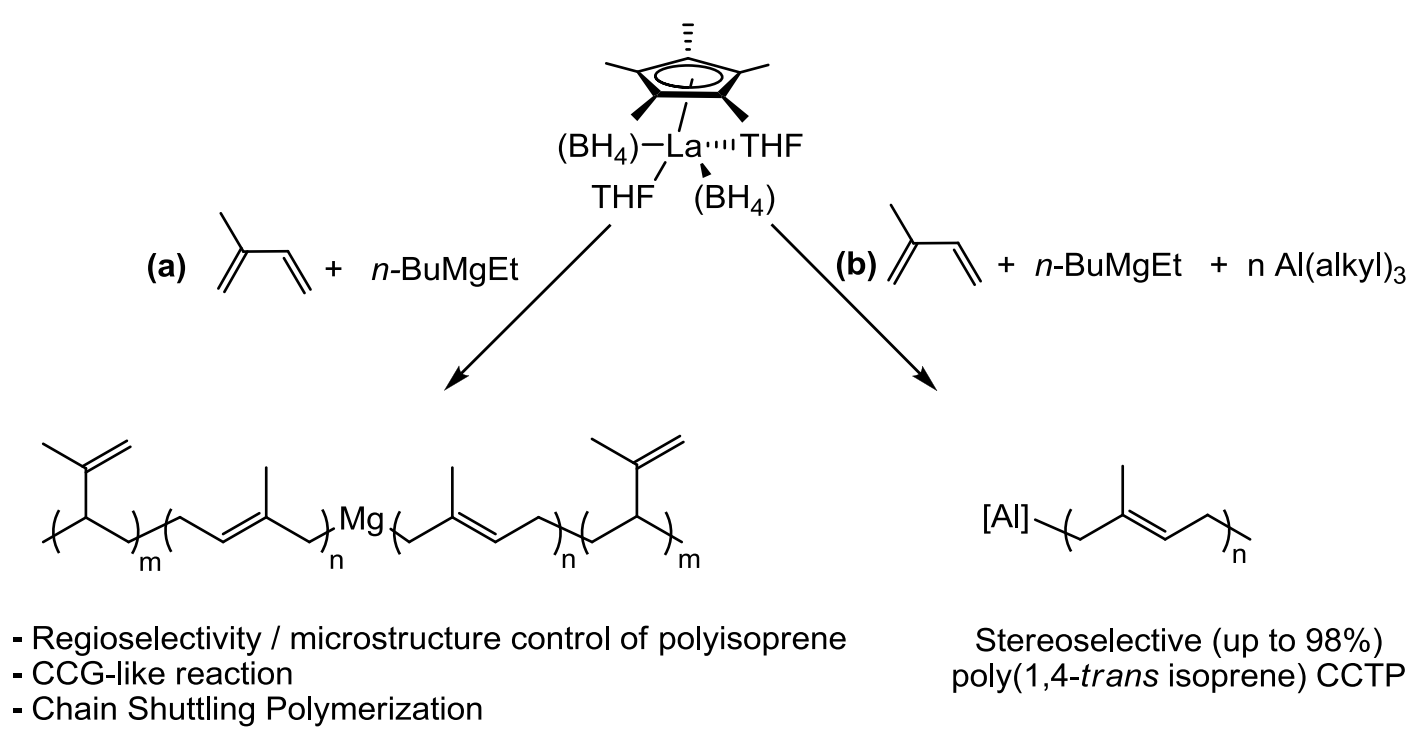

Scheme 22. Isoprene CCTP reactions using (a) $n$ BuMgEt and (b) $n \mathrm{Al}($ alkyl) 3 or $n \mathrm{AlH}^{i} \mathrm{Bu}_{2}$ as $\mathrm{CTA}^{69,73}$ 


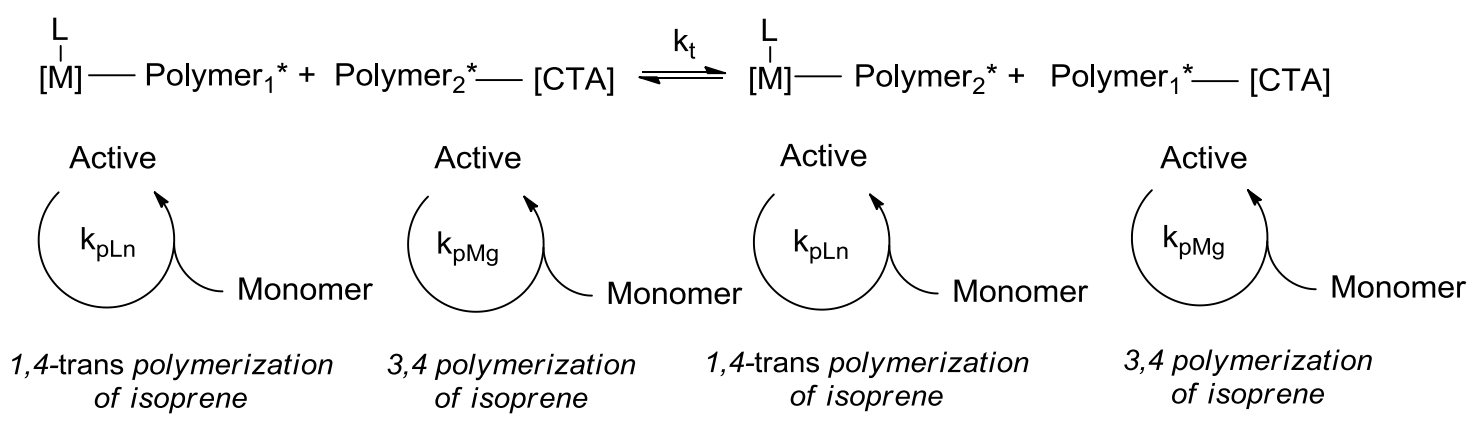

Scheme 23. Chain shuttling-like polymerization of isoprene using lanthanide based pre-catalysts and a magnesium dialkyl chain transfer agent able to co-oligomerize the monomers. ${ }^{69,73}$ Polymer* represents a growing polymeric chain, $M$ the metal allowing propagation, $L$ a ligand, and CTA the chain transfer agent. $k_{p L n}, k_{p M g}$ and $k_{t}$ are the rate constants for propagation on the lanthanide, propagation on magnesium and reversible transfer respectively.

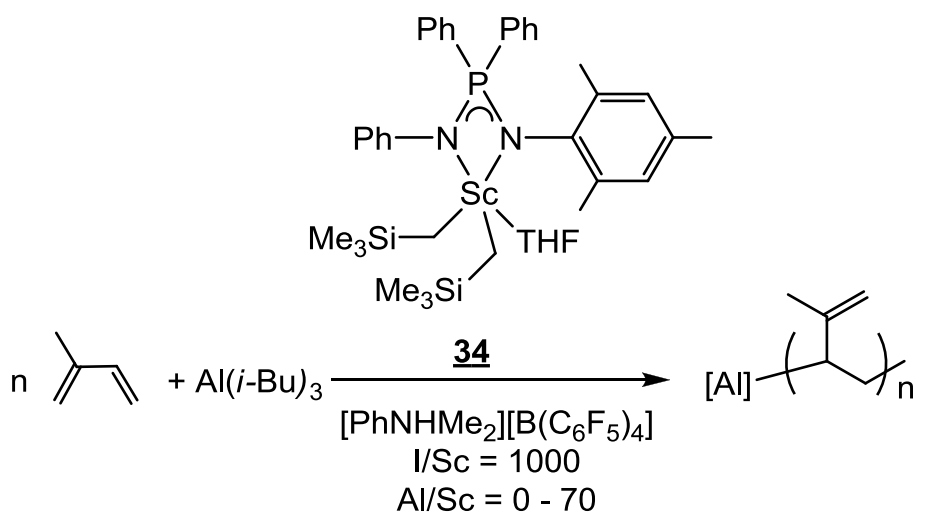

Scheme 24. 3,4 selective polymerization of isoprene using a Sc complex in combination with $\mathrm{Al}^{i} \mathrm{Bu}_{3} ;{ }^{76}$ reaction conducted at $-60-20{ }^{\circ} \mathrm{C}$; $\mathrm{I}=$ isoprene monomer. 


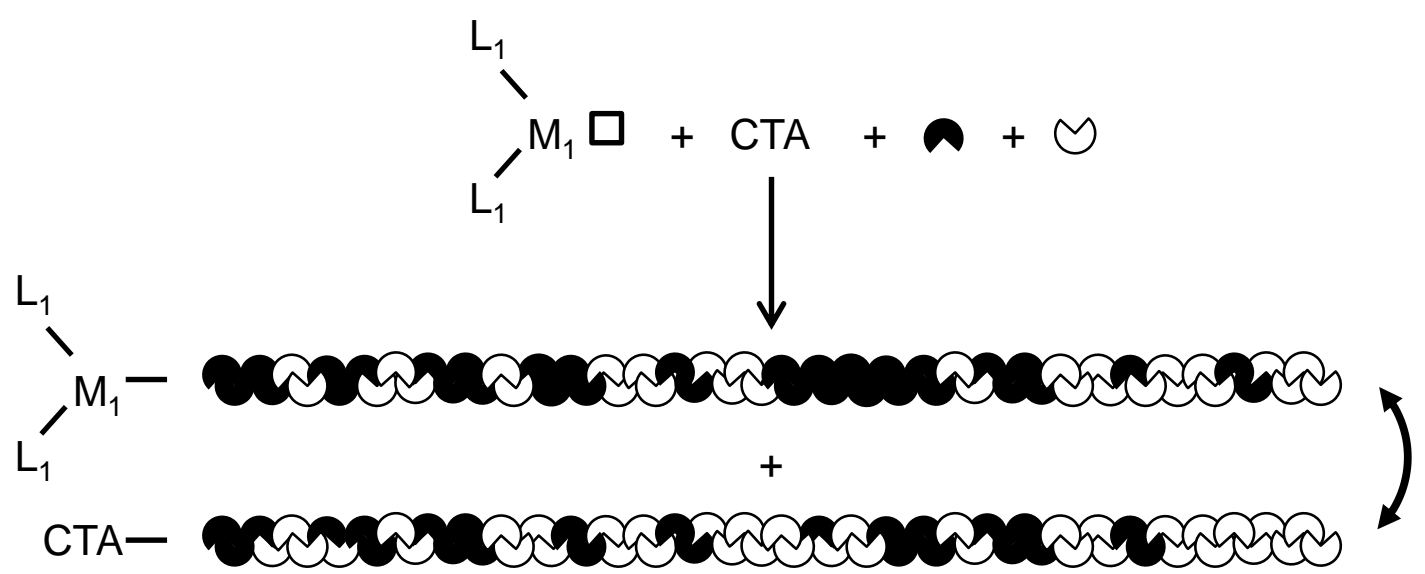

Scheme 25. Statistical copolymerization, where $\mathrm{M}=$ catalyst and CTA = chain transfer agent
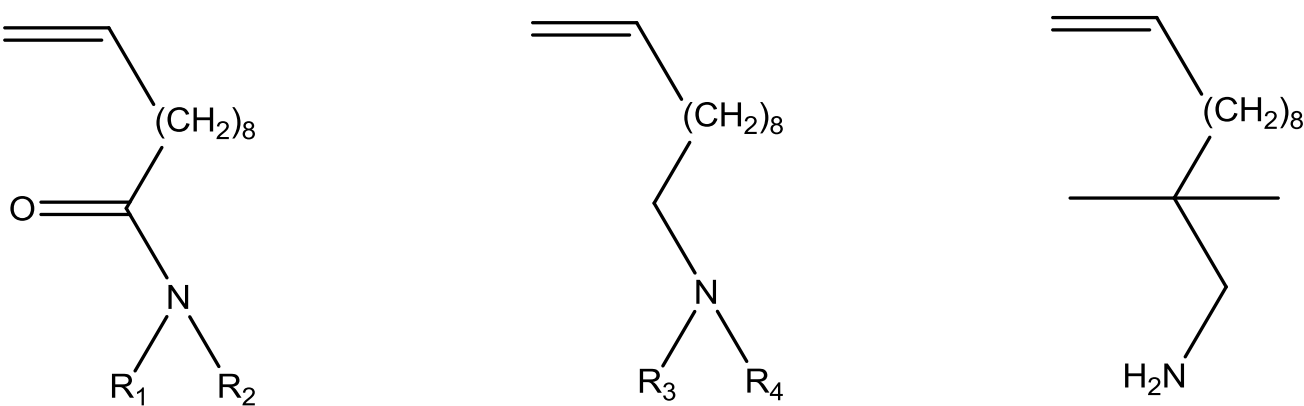

Scheme 26. Amide and amine functional alkenes. $R_{1-4}=H$, alkyl or benzyl.<smiles>C=CCC(C)(C)C</smiles>

Scheme 27. Formation of stable dimers with bridging Me groups between AlMe$_{6}$ and $\mathrm{AliBu}_{3}{ }^{87}$ 


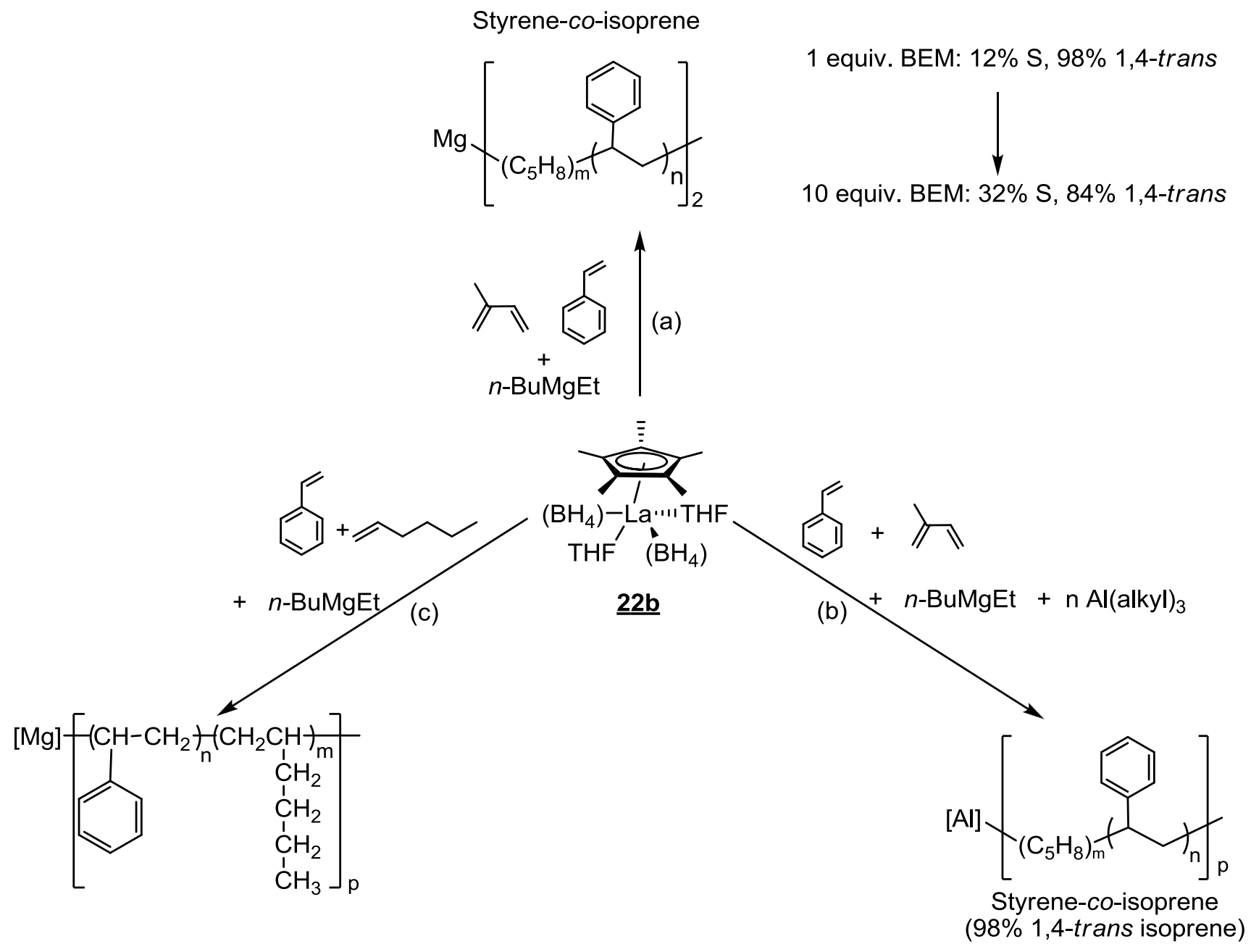

Scheme 28. Coordinative chain transfer copolymerizations of (a) Styrene and isoprene using $n \mathrm{BuMgEt}$ as $\mathrm{CTA}^{7^{73,88}}$ (b) Styrene and isoprene using 1 equiv. $n$ BuMgEt and $\mathrm{Al}(\text { alkyl })_{3}$ as $\mathrm{CTA}^{73,88}$ and (c) Styrene and 1-hexene using $n$ BuMgEt as $^{\text {CTA }^{89}}$ 

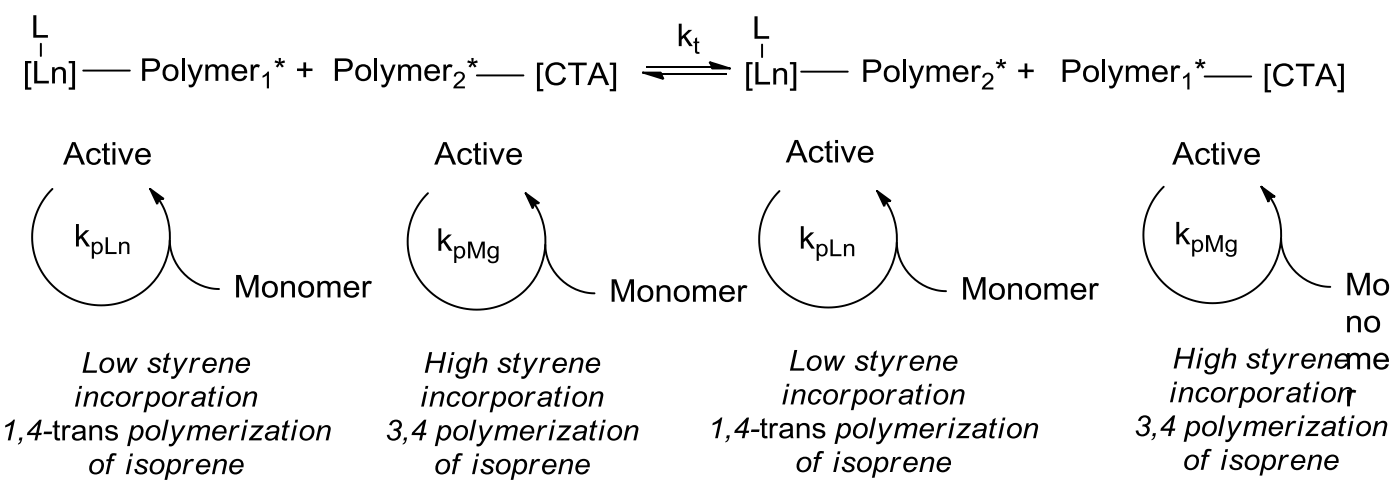

Scheme 29. Chain shuttling-like copolymerization of isoprene and styrene using lanthanide based pre-catalysts and a magnesium dialkyl chain transfer agent able to co-oligomerize the monomers. ${ }^{73,88}$ Polymer* represents a growing polymeric chain, $M$ the metal allowing propagation, $L$ a ligand, and CTA the chain transfer agent. $k_{p L n}, k_{p M g}$ and $k_{t}$ are the rate constants for propagation on the lanthanide, propagation on magnesium and reversible transfer respectively.

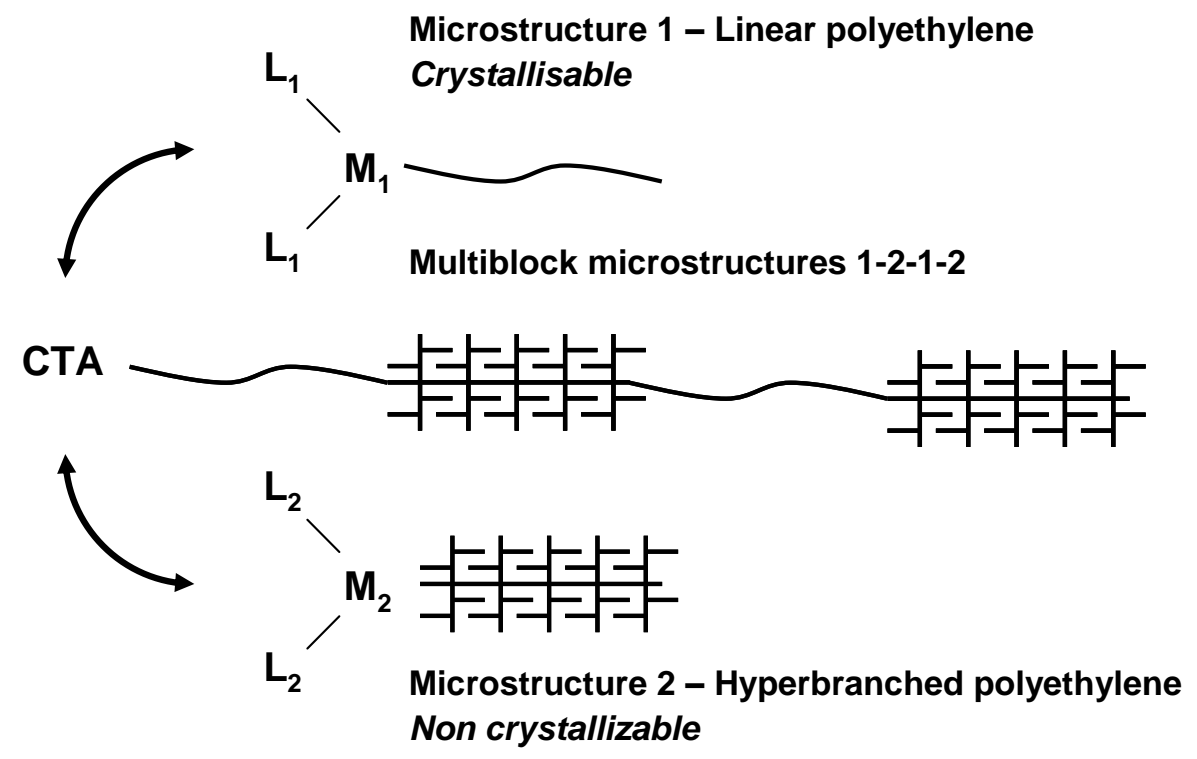

Scheme 30. Ethylene chain shuttling homopolymerization. ${ }^{96} M_{i}$ represents transition metals allowing propagation, $L_{i}$ ligands, and CTA the chain transfer or chain shuttling agent 


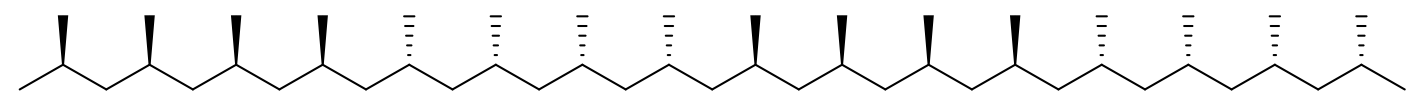

Scheme 31. Isotactic stereoblock polypropylene synthesized via chain shuttling polymerization $^{98}$

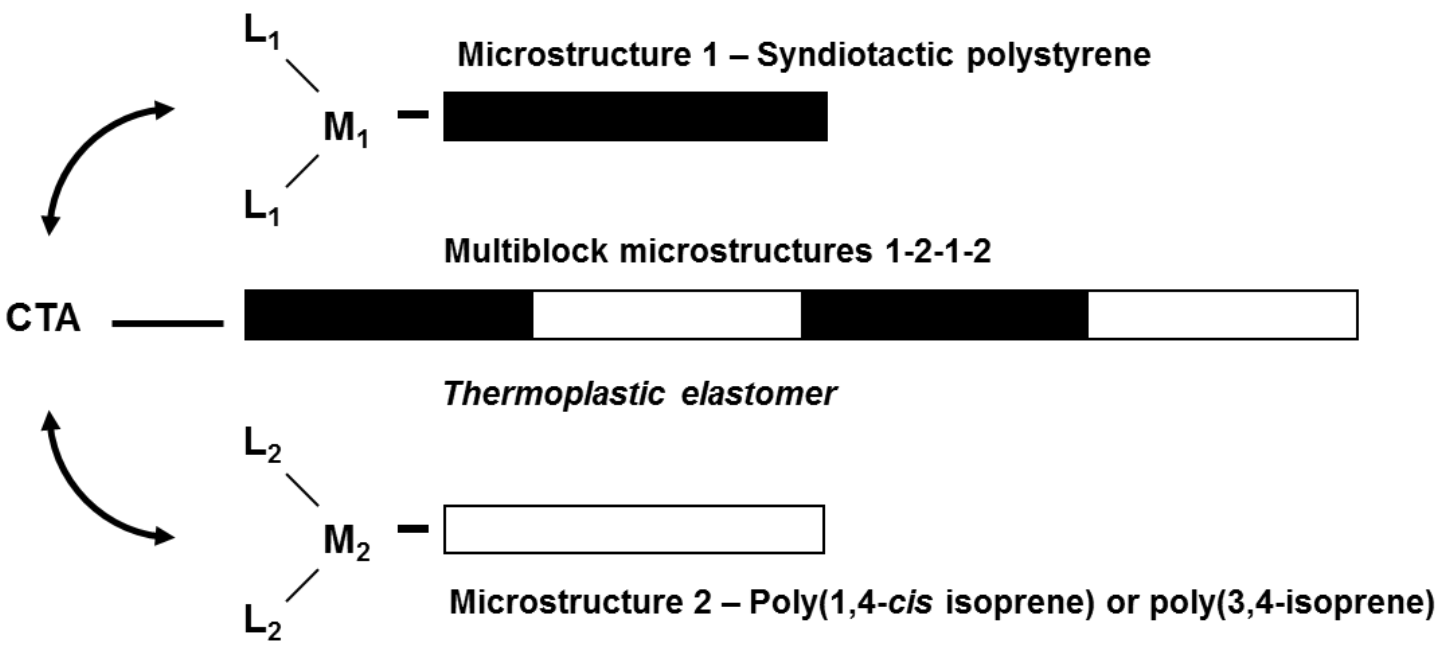

Scheme 32. Isoprene / styrene chain shuttling copolymerization leading to a multiblock microstructure of stereospecific homopolymers. ${ }^{105} \mathrm{M}_{\mathrm{i}}$ represents the scandium metal allowing propagation, $L_{i}$ ligands, and CTA the AliBu $\mathrm{Au}_{3}$ chain transfer or chain shuttling agent.

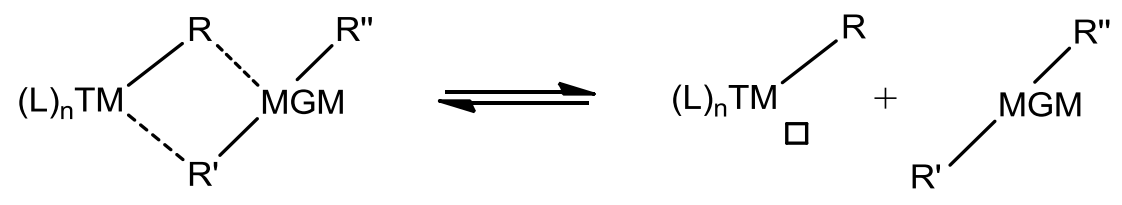

Scheme 33. Bimetallic active species involved in CCTP. TM represents a transition metal, MGM a main group metal, $L$ a ligand and $R, R^{\prime}, R^{\prime \prime}$ alkyl groups or macromolecular chains. 


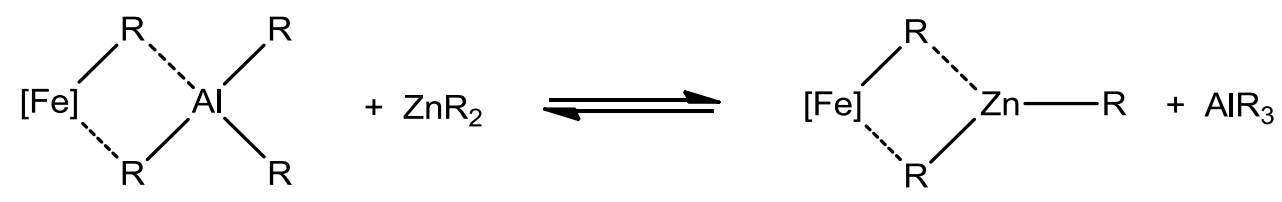

Scheme 34. Equilibrium between bridged bimetallics ${ }^{2}$ 


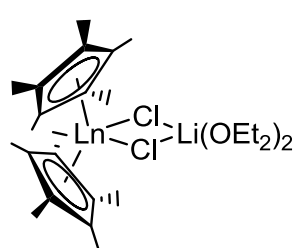

a: $\operatorname{Ln}=S m$

$\underline{1}$

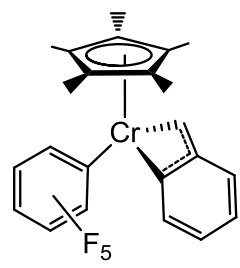

$\underline{5}$

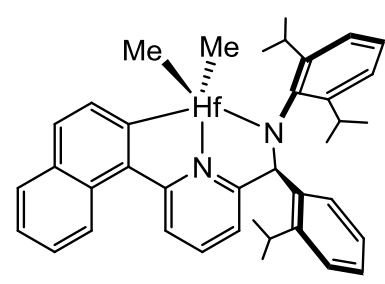

$\underline{9}$

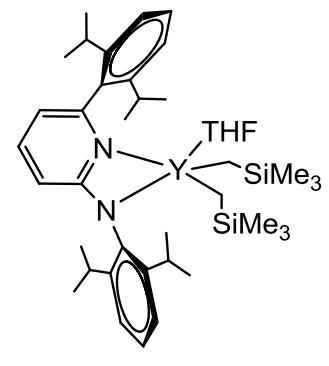

$\underline{2}$

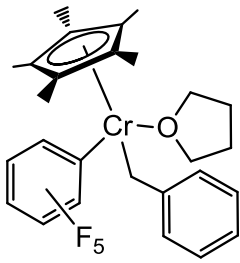

$\underline{6}$

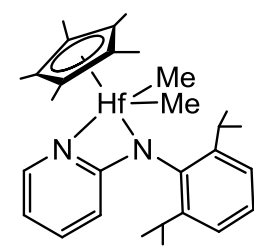

$\underline{10}$

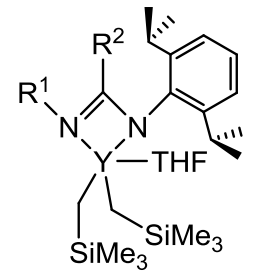

a: $\mathrm{R}^{1}=\mathrm{R}^{2}=2,4,6-\mathrm{Pr}_{3} \mathrm{C}_{6} \mathrm{H}_{2} \mathrm{C}=\mathrm{CHCH}=\mathrm{CH}$

b: $\mathrm{R}^{1}=2,6-\mathrm{Pr}_{2} \mathrm{C}_{6} \mathrm{H}_{3} ; \mathrm{R}^{2}=\mathrm{C}_{6} \mathrm{H}_{5}$

c: $\mathrm{R}^{1}=2,6-\mathrm{Pr}_{2} \mathrm{C}_{6} \mathrm{H}_{3} ; \mathrm{R}^{2}=\mathrm{Me}_{2} \mathrm{~N}$ $\mathrm{Pr}=$ iso-propyl

$\underline{3}$

$\underline{4}$

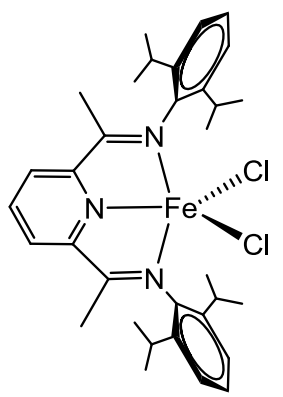

$\underline{7}$

$\underline{8}$
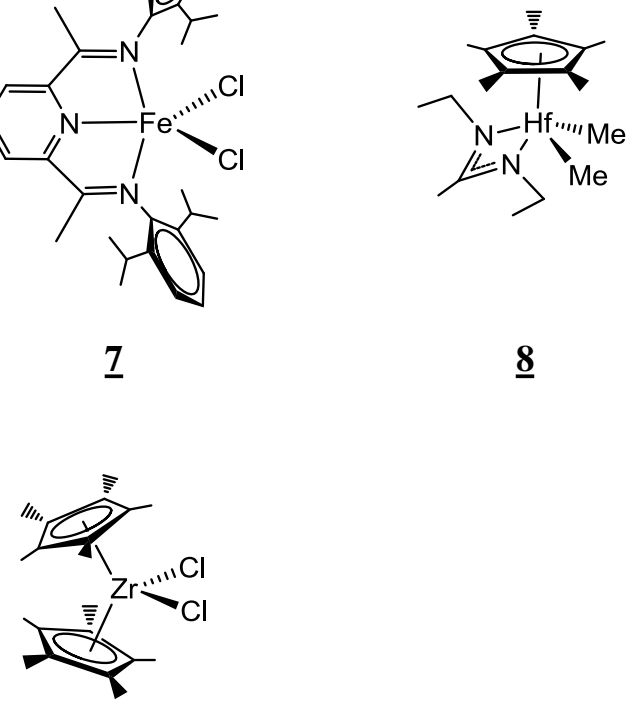

$\underline{11}$

Figure 1. Pre-catalysts used for ethylene CCTP 


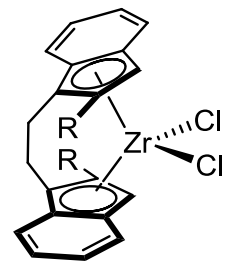

a: $\mathrm{R}=\mathrm{H}$

$\mathrm{b}: \mathrm{R}=t-\mathrm{BuMe}_{2} \mathrm{SiO}$

$\underline{12}$

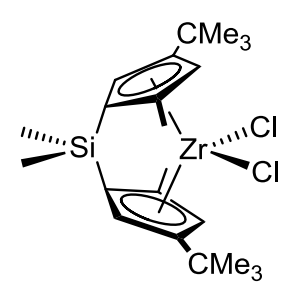

$\underline{16}$

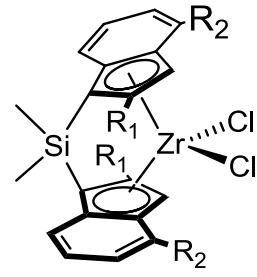

a: $\mathrm{R}_{1}=\mathrm{H} ; \mathrm{R}_{2}=\mathrm{H}$

b: $\mathrm{R}_{1}=\mathrm{CH}_{3} ; \mathrm{R}_{2}=\mathrm{H}$

$\underline{13}$

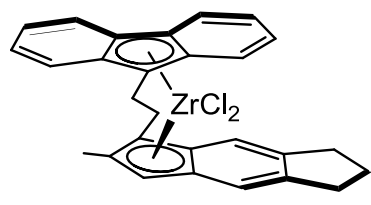

$\underline{17}$

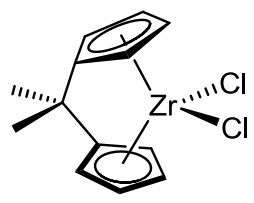

$\underline{14}$

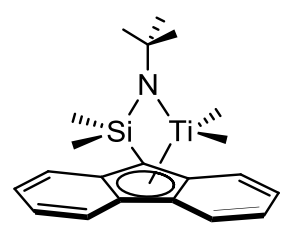

$\underline{15}$

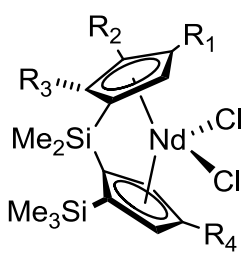

a: $\mathrm{R}_{1}=\mathrm{R}_{4}=t$-Bu; $\mathrm{R}_{2}=\mathrm{H} ; \mathrm{R}_{3}=\mathrm{SiMe}_{3}$

b: $\mathrm{R}_{1}=\mathrm{R}_{3}=\mathrm{R}_{4}=\mathrm{SiMe}_{3} ; \mathrm{R}_{2}=\mathrm{H}$

c: $R_{1}=R_{2}=R_{4}=S_{i M e} ; R_{3}=H$

Figure 2. Pre-catalysts used for propylene and higher 1-alkenes CCTP 


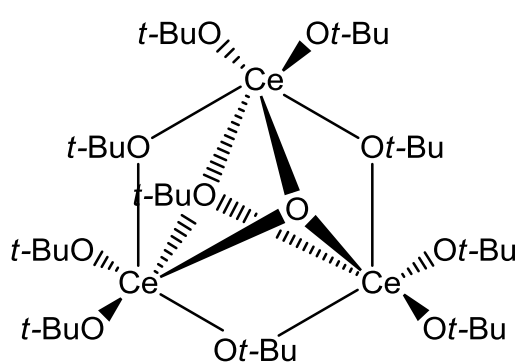

$\underline{19}$

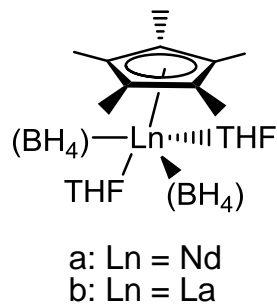

$\underline{22}$

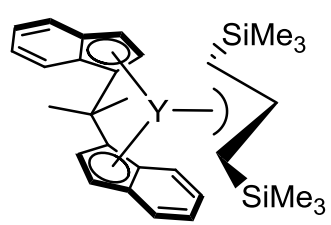

$\underline{25}$<smiles>[13CH3]O[13C](O[13CH3])(O[13CH3])O[13CH3]</smiles>

$\underline{20}$

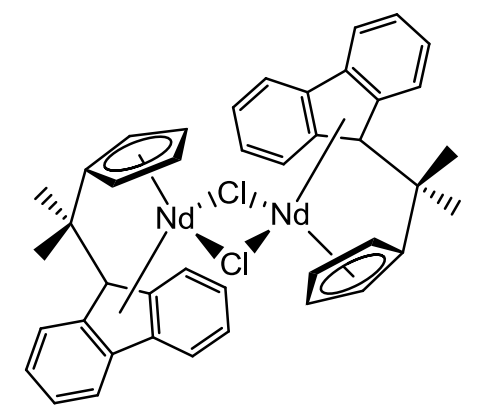

$\underline{23}$<smiles>Cl[Te](Cl)(Cl)(Cl)(Cl)C1CC1</smiles>

$\underline{27}$

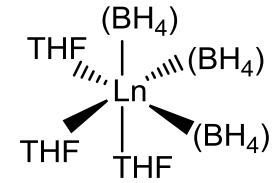

a: $\mathrm{Ln}=\mathrm{Nd}$

$\mathrm{b}: \mathrm{Ln}=\mathrm{La}$

c: $\operatorname{Ln}=S \mathrm{Sm}$

$\underline{21}$

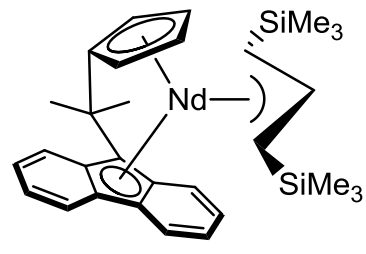

$\underline{24}$

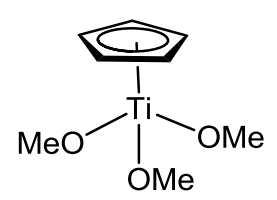

$\underline{28}$

Figure 3. Pre-catalysts used for styrene CCTP 


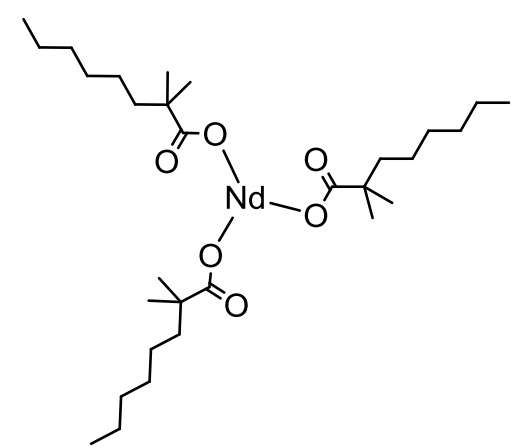

$\underline{29}$<smiles>CC(C)(C)c1cccc(C(C)(C)C)c1ON(Oc1c(C(C)(C)C)cccc1C(C)(C)C)Oc1c(C(C)(C)C)cccc1C(C)(C)C</smiles>

$\underline{32}$

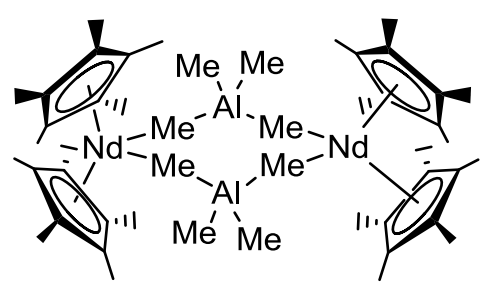

$\underline{30}$

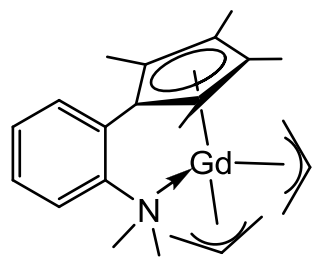

$\underline{33}$

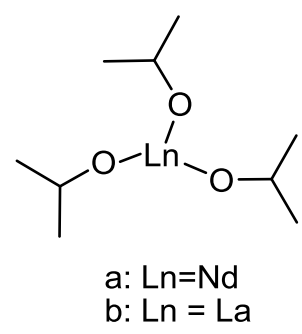

$\underline{31}$<smiles>C[SiH2]CC1(F)N([SiH2]C[Si](C)(C)C[SiH2]C)[PH](c2ccccc2)(c2ccccc2)N1c1c(C)cc(C)cc1F</smiles>

$\underline{34}$

Figure 4. Pre-catalysts used for conjugated dienes CCTP 


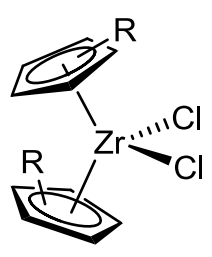

a: $\mathrm{RCp}=\mathrm{C}_{5} \mathrm{H}_{5}$

b: $\mathrm{RCp}=n-\mathrm{BuC}_{5} \mathrm{H}_{4}$

c: RCp $=2$-Melnd

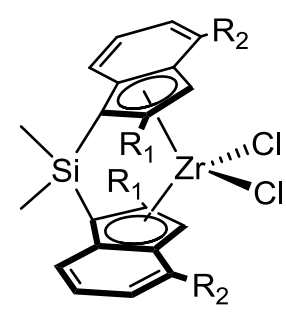

a: $\mathrm{R}_{1}=\mathrm{CH}_{3} ; \mathrm{R}_{2}=\mathrm{C}_{6} \mathrm{H}_{5}$

b: $\mathrm{R}_{1}=i-\operatorname{Pr} ; \mathrm{R}_{2}=m$-xyly

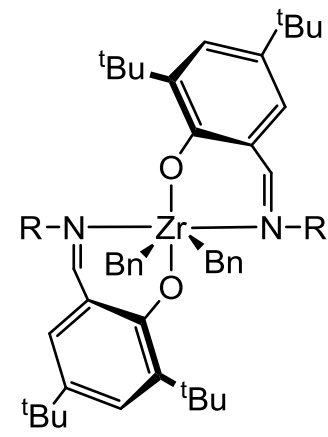

$\underline{37}$

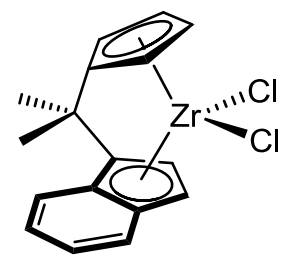

$\underline{38}$

$\underline{36}$<smiles></smiles>

$\underline{39}$

Figure 5. Pre-catalysts used for coordinative chain transfer copolymerizations 


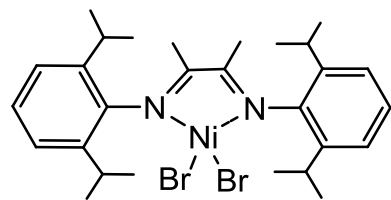

$\underline{40}$

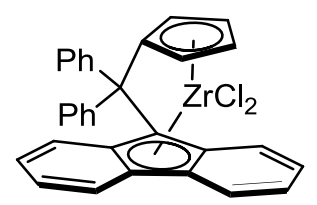

$\underline{41}$

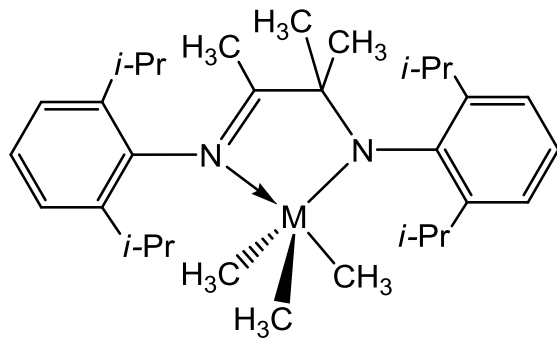

a: $M=\mathrm{Zr}$
b: $M=H f$

$\underline{42}$

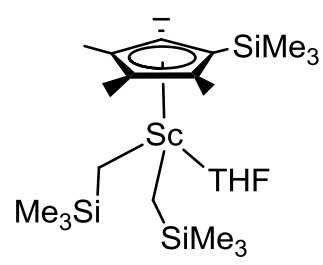

$\underline{45}$

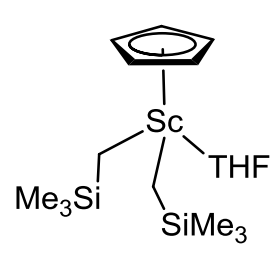

$\underline{46}$

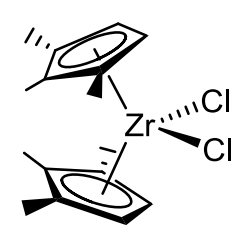

$\underline{44}$

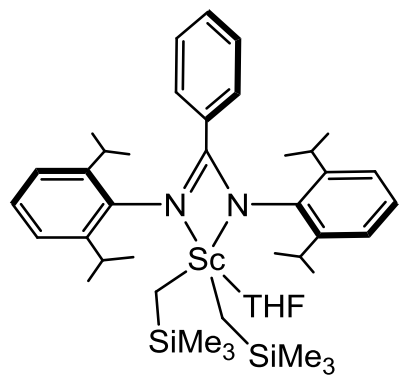

$\underline{47}$

Figure 6. Pre-catalysts used for Chain Shuttling polymerization 


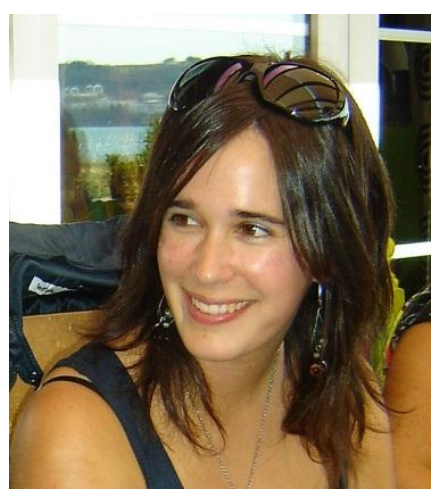

Andreia Valente is graduated in Technological Chemistry by the Faculty of Sciences from the University of Lisbon, Portugal. She continued her studies in this institution, where she got her Master degree in Biomedical Inorganic Chemistry. Then, she joined the Unity of Catalysis and Solid State Chemistry in Lille, France, where she obtained her PhD in 2010 in the field of Polymerization Catalysis. She moved back to Portugal where she is now postdoctoral researcher in the field of Polymeric Metal Complexes for biomedical applications. 


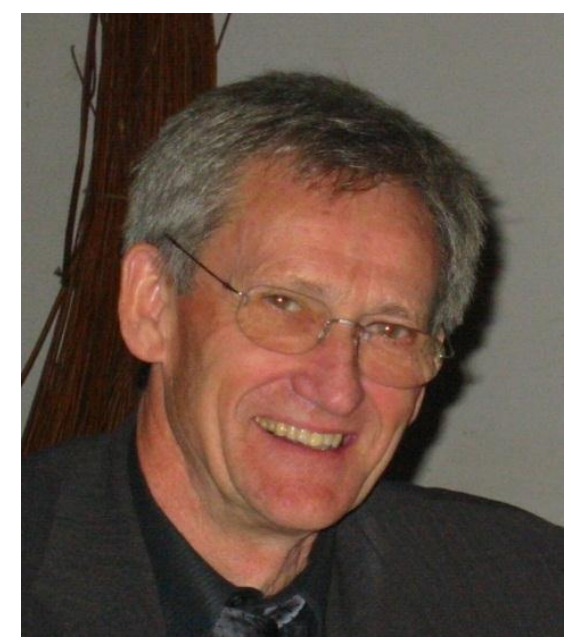

André Mortreux is currently Emeritus professor at Lille University. His former interest and achievement in homogeneous catalysis came from the discovery of the first homogeneous catalyst for alkyne metathesis in 1974 during his $\mathrm{PhD}$ mostly devoted to heterogeneous catalysis with Professor Blanchard in Poitiers. After a postdoctoral position in 1976 with Professor FGA Stone in Bristol, he moved back to Lille University to join his former colleague and friend Professor Petit to create a laboratory entirely devoted to Homogeneous Catalysis. His main research topics were then asymmetric catalysis (synthesis of new chiral ligands from the chiral poolaminophosphine phosphinite ligands ), the use of carbon monoxide and methyl formate as synthons for several carbonylation reactions (hydroformylation, hydroesterification, Fischer Tropsch synthesis ...), dimerization, polymerization and telomerization of dienes ( iron, nickel and palladium based catalysts), olefin metathesis (electrochemical synthesis of tungsten metallacarbene species ), olefin polymerization on titanium and lanthanide based catalysts, and more recently polyols catalyzed functionalizations within the frame of sustainable chemistry.

He his author and coauthor of more than 300 publications and 34 patents, and has been elected as a member of the Institut Universitaire de France in 2001 (Homogeneous Catalysis chair)

The search for new catalytic reactions has been one of his main interests all along his career: together with the discovery of the first catalyst for disubstituted alkyne metathesis, a further major achievement in this area has been the design of well-defined homogeneous catalyst for the challenging terminal alkyne metathesis. Another seminal discovery is the first evidence for a catalytic and reversible "living" transfer reaction between a lanthanidocene based catalyst and magnesium dialkyles during ethylene polymerization. This concept has been developed intensively during the last decade using other catalyst/transfer reagent couples on ethylene as well as on other substrates, and is nowadays mature enough to justify the present review. 


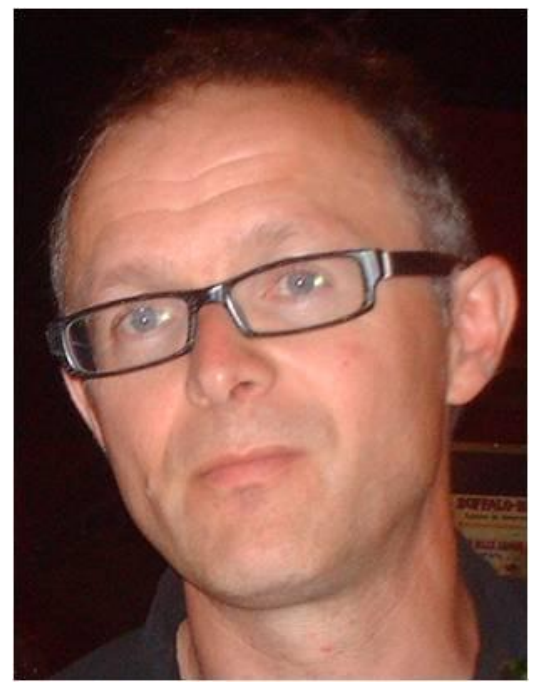

Marc Visseaux received the degree of "Docteur de l'Université de Dijon" (Burgundy, France) in 1992, under the supervision of D. Barbier-Baudry. After a position of Maitre de Conferences in Dijon, he obtained his "Habilitation à Diriger des Recherches" in 2000. He was appointed full Professor in 2003 at the University of Science and Technology of Lille (USTL) in the group of A. Mortreux.

Marc Visseaux is since 2005 head of the Polymerization Catalysis Team of UCCS (Unité de Catalyse et Chimie du Solide, UMR 8181 CNRS). During his scientific career, Marc Visseaux moved from fundamental organometallic chemistry of the rare earths at the very beginning, to applications in polymerization catalysis, and finally today to the elaboration of specialty polymers by means of molecular catalysis. His fields of interest include organometallic chemistry of the lanthanides, synthesis of tailor-made coordination rare-earths catalysts, mechanistic investigations including theoretical aspects, Ziegler-Natta type polymerization catalysis and Ring Opening Polymerization with low valent f-element initiators. Marc Visseaux spent a sabbatical period in 2009 as an Invited Professor in Polly L. Arnold's group in Edinburgh. 


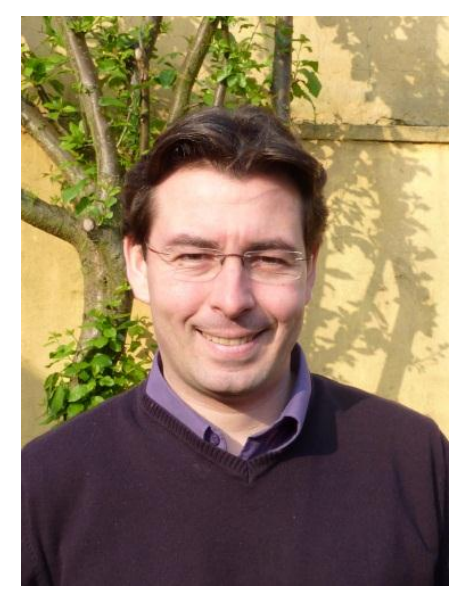

Philippe Zinck was graduated and obtained his $\mathrm{PhD}$ from the National Institute of Applied Science in Lyon in 1999. He was then awarded an individual Marie Curie Fellowship for a post-doctoral position at the Weizmann Institute of Science. After postdoctoral stays at the Polytechnic Federal School of Lausanne and at the Ecole Supérieure de Physique et Chimie Industrielles de la Ville de Paris, he joined the Unity of Catalysis and Solid State Chemistry, University of Lille in 2004 where he is currently Professor. He is member of the French Chemical Society (North section Board), the French Group of Polymer (North section Board), the Marie Curie Fellowship Association (Advisory Board) and the Editorial Board of the journals Polymer Science and Reviews in Environmental Science and Biotechnology as Science Career Editor. His current research interests concerns polymerization catalysis. 